\title{
A model for the benthic-pelagic coupling of silica in estuarine ecosystems: sensitivity analysis and system scale simulation
}

\author{
S. Arndt and P. Regnier \\ Department of Earth Sciences, University of Utrecht, Utrecht, The Netherlands \\ Received: 19 February 2007 - Published in Biogeosciences Discuss.: 2 March 2007 \\ Revised: 10 May 2007 - Accepted: 1 June 2007 - Published: 19 June 2007
}

\begin{abstract}
A transient, vertically resolved, analytical model for the early diagenesis of silica has been developed to quantify the importance of benthic-pelagic coupling in estuarine biogeochemical silica cycling. A sensitivity analysis based on Monte-Carlo simulations is carried out to assess the intensity and timing of benthic diffusive fluxes in response to a pelagic diatom bloom. The diffusive flux dynamics are analyzed over a realistic range of dissolution rate constants $\left(\max k_{\mathrm{Si}} \in\left[6 \times 10^{-3}-3.6 \times 10^{-1} \mathrm{~d}^{-1}\right]\right.$ ), diffusion coefficients of dissolved silica $\left(D_{\mathrm{Si}} \in\left[35 \times 10^{-6}-35 \times 10^{-5} \mathrm{~m}^{2} \mathrm{~d}^{-1}\right]\right)$ and duration of dissolved silica depletion in the water column ( $w_{\text {PDSI }} \epsilon$ [1-3 month]). Results show that the diffusive silica flux responds with a time delay of 20 to 120 days to the biogenic silica deposition pulse. For high $\max k_{\mathrm{Si}}$, simulated time lags are shortest and completely determined by the dissolution kinetics. However, decreasing $\max k_{S i}$ leads to a slower benthic flux response. In addition, the variability increases due to the increasing importance of transport processes. The sensitivity study also allows us to constrain the uncertainties of a system-scale simulation, where a large number of benthic compartments $(>50000)$ are coupled to a high-resolution $(100 \times 100 \mathrm{~m})$ pelagic model of a macrotidal river and estuary (Western Scheldt, B/NL). The model is applied to a diatom bloom event recorded in 2003, characterized by pelagic silica depletion in August. Benthic processes are mainly modulated by the combined influence of local hydrodynamic conditions and pelagic primary production dynamics, and show therefore a high degree of spatial heterogeneity over short distances. Spatially integrated deposition fluxes and dissolution rates of biogenic silica are high throughout the growth period, with maxima of $1.3 \times 10^{5} \mathrm{~mol} \mathrm{~d}^{-1}\left(=8.0 \mathrm{mmol} \mathrm{m}^{2} \mathrm{~d}^{-1}\right)$ and $7.8 \times 10^{4} \mathrm{~mol} \mathrm{~d}^{-1}$ $\left(=4.8 \mathrm{mmol} \mathrm{m}^{2} \mathrm{~d}^{-1}\right)$ in mid-August. The spatially integrated diffusive flux reaches a maximum of $1.5 \times 10^{4} \mathrm{~mol} \mathrm{~d}^{-1}$ at the
\end{abstract}

Correspondence to: S. Arndt

(s.arndt@geo.uu.nl) end of a pelagic silica depletion period in September. However, the total amount of dissolved silica released from the estuarine sediments between June and December 2003 is small $\left(2 \times 10^{6} \mathrm{~mol}\right)$ compared to the much higher riverine influx of dissolved silica $\left(5.9 \times 10^{7} \mathrm{~mol}\right)$ and plays a minor role in the pelagic primary production dynamics.

\section{Introduction}

The transport of nutrients in river and estuarine systems is of major importance for the understanding of the phytoplankton bloom dynamics in coastal waters. While the estuarine biogeochemical cycles of nitrogen and phosphorous are comparatively well-studied (e.g. Soetaert and Herman , 1995; Conley et al., 1995; Trimmer et al., 1998; Uncles et al., 1998; Abril et al., 2000; McKee et al., 2000; Dettman, 2001), the estuarine silica cycle has received less attention. Silica limitation can however be an important trigger for the phytoplankton succession in coastal waters and may induce the development of toxic algal blooms (Townsend et al., 2001; Rousseau et al., 2002; Lancelot et al., 2005).

In diatom-dominated estuaries, subject to high phosphorous and nitrogen loadings, silica is often the limiting nutrient. Therefore, the riverine silica input can be significantly, or even completely, consumed by the biomineralization of biogenic silica during the peak stages of the estuarine diatom bloom (e.g. Garnier et al., 1995; Malone et al., 1996; Domingues et al., 2005; Arndt et al., 2007). In such systems, the benthic recycling of deposited biogenic silica may become an important pathway in the estuarine silica cycle (Struyf et al., 2005). The resulting benthic-pelagic coupling operates in two directions. On the one hand, pelagic diatom blooms trigger a depositional flux of labile phytodetritus, which initiate the recycling processes in the estuarine sediments. On the other hand, the benthic return flux may sustain primary production at the terminal stage of the bloom, which

Published by Copernicus Publications on behalf of the European Geosciences Union. 
is often characterized by limiting nutrient conditions (Koop et al., 1990; Cowan and Boynton, 1996; Trimmer et al., 1998; Grenz et al., 2000). Observations reveal a large spatial and temporal variability in the intensity and timing of this benthic flux response (Hansen and Blackburn, 1992; Hall et al., 1996; Tuominen et al., 1996; Sakamaki et al., 2006; Vidal and Morgui, 2000). The strength of the benthic-pelagic coupling is controlled by the dissolution kinetics and the diffusive transport, which are both time-dependent processes (Vidal and Morgui, 2000; Sakamaki et al., 2006). The diffusive exchange strongly depends on the physical conditions at the sediment-water interface, which generally exhibit a very high degree of heterogeneity over short distances. Shallow tidal flats, characterized by low energy and net deposition, coexist with relatively deep tidal channels, where conditions of high energy and net erosion prevail. Unlike pelagic silica concentrations, which are efficiently mixed by tidal mixing, benthic concentrations are thus strongly dependent on the local physical conditions. Therefore, the benthic-pelagic coupling reveals a pronounced two-dimensional pattern with large differences in benthic fluxes between sites (Grenz et al., 2000). In addition, the benthic nutrient regeneration fluxes show large variabilities over a broad range of timescales. A distinct seasonal signal is triggered by the pelagic primary production cycles (Vidal and Morgui, 2000). Furthermore, Sakamaki et al. (2006) observed important fluctuations at the tidal time scale in two estuarine tidal flats, which result from the tidal variations in overlying water composition.

Estuaries are extremely dynamic environments where diagenetic transformations are tightly linked to solute and sediment transport processes, leading to rapidly changing boundary conditions at the sediment/water interface. In addition, they are often conducted on easily accessible, shallow intertidal flats where deposition of particulate matter might be strongly favored. The extrapolation of these experimentallyderived benthic fluxes to the scale of an entire ecosystem, may therefore result in a significant overestimation of the total benthic silica flux. Reactive-transport models (RTMs) constitute a useful alternative as they provide a powerful tool to resolve the spatio-temporal heterogeneity intrinsic to the benthic environment. Yet, many existing RTMs currently contain no or highly conceptualized descriptions of benthic processes. The spectra of diagenetic model approaches which have been incorporated in RTMs of estuarine and coastal systems so far include, in order of increasing complexity, imposed benthic fluxes; reflective boundary conditions (Soetaert and Herman, 1995a; Regnier et al., 1997; Fennel et al., 2005); dynamic vertically, integrated models (Baird, 2001; Lee et al., 2002) and vertically resolved, dynamic models (Blackford, 1997; Luff and Moll, 2004).

To cope with the complexity of benthic processes, a transient, vertically resolved, numerical diagenetic model would be the most accurate approach. However, the high computational cost of these models renders this solution unpractical at the system-scale. In this study, a robust, analytical and, therefore, cost-efficient method which captures the transient dynamics of dissolved and solid benthic silica in a vertically resolved model is presented as an alternative. The model is used to investigate the dynamics of benthic silica cycling on a seasonal time scale as a response to a bloom event. The sensitivity of the magnitude and the timing of benthic fluxes to variations in internal parameters and external forcing conditions is assessed. The results of this sensitivity study provide a framework for the evaluation of uncertainties associated to the benthic flux estimates. The benthic silica module is then coupled to a two-dimensional reactive transport model of the macrotidal Scheldt estuary (Belgium/The Netherlands). Little is known about the benthic recycling of silica in the Scheldt estuary. Struyf et al. (2005) argue that freshwater marshes are important silica recyclers which act as a source of dissolved silica that is compensated by a net-import of biogenic silica. By extrapolating the export fluxes observed at two study sites to the entire area of freshwater marshes, they estimated that during summer months, almost half of the total dissolved silica load in the main channel can result from marsh recycling. However, the few available field observations cannot resolve the strong spatial heterogeneity and the temporal variability of the benthic-pelagic coupling in the estuary. The coupled model accounts for these variabilities and therefore allows to evaluate the spatial and temporal patterns of benthic-pelagic coupling, as well as the importance of benthic-pelagic coupling for primary production. System scale simulations are performed for the summer of 2003. This period was chosen due to the prevailing, extremely dry conditions, hypothesized to favor the influence of the benthic-pelagic coupling on the pelagic primary production dynamics in the Scheldt (Desmit, 2005a; Van Damme et al., 2005; Muylaert et al., 2000).

\section{Model description}

\subsection{Benthic model}

Ruardij and Van Raaphorst (1995) and Ebenhöh et al. (1995) have proposed a robust, analytical and, therefore, costefficient method to capture the early diagenesis of biogenic and dissolved benthic silica in a vertically resolved model. The description of the benthic silica cycle adopted here basically follows their main concept which aggregates essential processes. However, the detailed formulation of erosion, deposition and burial processes, as well as the description of dissolved silica differ from their approach.

The model is based on the assumption that the depth profile of benthic biogenic silica (BBSI) in the sediment follows an exponential decrease, which is cut off at a maximum depth in the sediment, $z_{\max }$, and normalized to the depth integrated

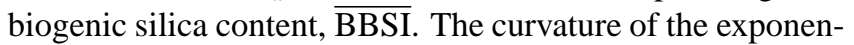
tial function is determined by the mean intrusion depth, ID. 
The vertical profile of BBSI is therefore completely determined by two dynamic parameters, $\overline{\mathrm{BBSI}}$ and ID:

$$
\operatorname{BBSI}(z, t)=\frac{\overline{\operatorname{BBSI}}(t)}{\operatorname{ID}(t)\left(1-e^{\left(-\frac{z \max }{\mathrm{ID}(t)}\right)}\right)} e^{\left(-\frac{z}{\mathrm{ID}(t)}\right)}
$$

where:

$\mathrm{ID}(t)=\frac{1}{\overline{\operatorname{BBSI}}(t)} \int_{0}^{z_{\max }} z \times \operatorname{BBSIO}(z, t) \times d z$

ID and thus the depth distribution of BBSI, change dynamically according to a number of different consumption/production processes, $\bar{P}_{i}$. The processes considered in the model are the dissolution (diss), bioturbation (biot), deposition (dep), erosion (ero) and burial (burial) of biogenic silica. The depth-integrated biogenic silica content in the sediments is given by:

$$
\frac{d}{d t} \overline{\mathrm{BBSI}}=\sum_{i} \overline{P_{i}}
$$

$\overline{\mathrm{BBSI}}$ increases due to the deposition flux of pelagic biogenic silica $\left(\bar{P}_{\text {dep }}\right)$. This deposition flux is either imposed as a boundary forcing, or it is obtained as outcome of a coupled pelagic model. Silica dissolution $\left(\bar{P}_{\text {diss }}\right)$ consumes BBSI and is assumed to follow a first-order rate law with respect to BBSI. $\bar{P}_{\text {diss }}$ also depends on the degree of saturation of the pore waters with respect to the solid phase (Hurd, 1973; Schink et al., 1975; Wollast and Mackenzie, 1983). Accordingly, the depth-integrated dissolution rate of biogenic silica is given by:

$\bar{P}_{\text {diss }}(t)=\int_{0}^{z_{\max }} k_{\mathrm{Si}}(T) \times \operatorname{BBSI}(z, t) \times\left(1-\frac{\operatorname{BDSI}(z, t)}{\operatorname{BDSI}_{\mathrm{sat}}}\right) d z$

where BDSI is the concentration of dissolved silica, BDSI ${ }_{\text {sat }}$ is the apparent silica solubility and $k_{\mathrm{Si}}$ is the first-order rate constant of dissolution. The temperature-dependence of the rate constant $k_{\mathrm{Si}}$ is described by the Arrhenius equation (e.g Van Cappellen and Qiu, 1997; Icenhower and Dove, 2000):

$k_{\mathrm{Si}}(T)=k_{0} \times e^{-\frac{E_{a}}{R \times T}}$

where $T$ is the absolute ambient temperature, $k_{0}$ is the preexponential factor, $E_{a}$ is the empirical activation energy and $R$ is the gas constant. The resuspension and burial fluxes of BBSI are directly coupled to the local suspended particulate matter (SPM) dynamics. Erosion and burial fluxes of BBSI for each time step of the numerical integration $\Delta t$ are determined by integration of Eq. (1) over the depth of the eroded and the buried sediment layers:

$$
\begin{aligned}
\bar{P}_{\text {ero }}(t) & =\frac{1}{\Delta t} \times \int_{0}^{z_{\text {ero }}} \operatorname{BBSI}(z, t) d z \\
\bar{P}_{\text {burial }}(t) & =\frac{1}{\Delta t} \times \int_{z_{\max }-z_{\text {dep }}}^{z_{\max }} \operatorname{BBSI}(z, t) d z
\end{aligned}
$$

The thicknesses of the eroded $\left(z_{\mathrm{ero}}\right)$ and deposited $\left(z_{\mathrm{dep}}\right)$ layers are determined by the sediment erosion and deposition rates according to:

$$
\begin{aligned}
z_{\text {ero }} & =\frac{\phi}{(1-\phi) \rho} \times R_{\text {ero }} \times \Delta t \\
z_{\text {dep }} & =\frac{\phi}{(1-\phi) \rho} \times R_{\text {dep }} \times \Delta t
\end{aligned}
$$

where $\phi$ denotes the porosity of the sediments and $\rho$ represents the sediment density. $R_{\text {ero }}$ and $R_{\text {dep }}$ are the erosion and deposition rate of sediment, respectively. They are given as a boundary forcing or directly calculated in the case of a coupled benthic-pelagic model (see below).

Consumption/production processes are a complex function of depth. Yet, an average consumption/production depth, $\mathrm{ID}_{i}$ can be defined for each process $i$ in a similar way to Eq. (2).

$\operatorname{ID}_{i}(t)=\frac{1}{\overline{P_{i}}(t)} \int_{0}^{z_{\max }} z \times P_{i}(z, t) \times d z$

The temporal evolution of ID is then obtained by applying the principle of conservation of mass and of the center of mass (Ebenhöh et al., 1995):

$\frac{d}{d t} \mathrm{ID}=\sum_{i} \frac{d}{d t} \mathrm{ID}_{i}$

where

$$
\begin{aligned}
\frac{d}{d t} \mathrm{ID}_{\text {diss }} & =\left(\mathrm{ID}_{\text {diss }}-\mathrm{ID}\right) \times \frac{\bar{P}_{\text {diss }}}{\overline{\mathrm{BBSI}}} \\
\frac{d}{d t} \mathrm{ID}_{\text {dep }} & =\left(\mathrm{ID}_{\mathrm{dep}}-\mathrm{ID}\right) \times \frac{\bar{P}_{\text {dep }}}{\overline{\mathrm{BBSI}}} \\
& +\frac{z_{\text {dep }} / \Delta t \times \overline{\mathrm{BBSI}}-\mathrm{ID} \times \bar{P}_{\text {dep }}}{\overline{\mathrm{BBSI}}} \\
\frac{d}{d t} \mathrm{ID}_{\text {ero }} & =\left(\mathrm{ID}_{\text {ero }}-\mathrm{ID}\right) \times \frac{\overline{P_{\text {ero }}}}{\overline{\mathrm{BBSI}}} \\
& +\frac{z_{\text {ero }} / \Delta t \times \overline{\mathrm{BBSI}}-\mathrm{ID} \times \bar{P}_{\text {ero }}}{\overline{\mathrm{BBSI}}} \\
\frac{d}{d t} \mathrm{ID}_{\text {burial }} & =\left(\mathrm{ID}_{\text {burial }}-\mathrm{ID}\right) \times \frac{\overline{P_{\text {burial }}}}{\overline{\mathrm{BBSI}}} \\
\frac{d}{d t} \mathrm{ID}_{\text {biot }} & =\frac{\xi \times \Delta}{\mathrm{ID}} \times\left(1-e^{-\frac{\xi}{\mathrm{ID}}}\right)
\end{aligned}
$$


The deposited/removed material is considered homogeneously distributed within the respective layers. The effect of bioturbation on the intrusion depth $\left(\frac{d}{d t} \mathrm{ID}_{\text {biot }}\right)$ is quantified assuming that a sediment layer $\Delta$ is exchanged between the sediment surface and a bioturbation depth, $\xi$ and therefore $D_{b i o}=\xi \times \Delta$ (Ebenhöh et al., 1995). Erosion, burial and bioturbation generally lead to an increase of ID, while the deposition of biogenic silica at the sediment/water interface results in a reduction of ID. The influence of $P_{\text {diss }}$ on ID depends on the distribution of BBSI in the sediment and $P_{\text {diss }}$ can shift ID in both directions.

The dissolution of BBSI leads to a build up of BDSI, which migrates in the sediment column. The simulation of BDSI depth profiles is based on the diagenetic equation for solute species (e.g. Berner, 1980):

$$
\begin{aligned}
\frac{\partial \mathrm{BDSI}}{\partial t} & =D_{\mathrm{Si}}^{\prime} \frac{\partial^{2} \mathrm{BDSI}}{\partial z^{2}} \\
& +k_{\mathrm{Si}}(T) \times \frac{1-\phi}{\phi} \times \mathrm{BBSI}(z, t) \times\left(1-\frac{\mathrm{BDSI}}{\mathrm{BDSI}_{\mathrm{sat}}}\right)
\end{aligned}
$$

where $D_{\mathrm{Si}}$ denotes the apparent diffusion coefficient for BDSI and $\phi$ represents the constant porosity of the sediment. It is assumed that advection of pore waters is small compared to the diffusional fluxes, which results from the combined action of molecular diffusion, bioturbation, as well as wave and current action. The diffusive flux at the sediment/water interface $\left(F_{\mathrm{Si}}\right)$ is given by:

$$
F_{\mathrm{SI}}=-\phi \times D_{\mathrm{Si}} \times\left.\frac{\partial \mathrm{BDSI}}{\partial z}\right|_{z=0}
$$

Equation (17) can not be solved analytically for the nonsteady state case but has an analytical solution for steady state conditions. After a change of variables $(C(z)=$ $\left.\operatorname{BDSI}_{\mathrm{sat}}-\operatorname{BDSI}(z)\right)$, the steady state solution $C_{s s}(z)$ is given by a hyperbolic Bessel function of the first kind of order zero, $I_{0}$ (Abramowitz and Stegun, 1972):

$$
C(z)_{s s}=c \times I_{0}\left(\lambda \times e^{-\frac{z}{2 \times \mathrm{ID}}}\right)
$$

where $c$ denotes an integration constant and $\lambda$ is:

$$
\lambda=2 \times \mathrm{ID} \sqrt{\frac{k_{\mathrm{Si}}}{D_{\mathrm{Si}}^{\prime} \times \mathrm{BDSI}_{\mathrm{sat}}} \times \frac{\overline{\mathrm{BBSI}}}{\mathrm{ID}\left(1-e^{-\frac{2 \mathrm{max}}{\mathrm{ID}}}\right)}}
$$

A relaxation between the solution at the previous time step of the numerical integration, $C(z, t-\Delta t)_{t r}$, and the steady state solution at the actual time step, $C(z, t)_{s s}$, approximates the non-steady state solution, $C(z, t)_{t r}$ (Ruardij and Van Raaphorst, 1995):
$C(z, t)_{t r}=C(z, t)_{s s}+\left(C(z, t-\Delta t)_{t r}-C(z, t)_{s s}\right) e^{-\frac{\Delta t}{t_{a}}}$

where the adaption time $\left(t_{a}\right)$ is given by (Ruardij and Van Raaphorst, 1995):

$t_{a}=\frac{1}{k_{\mathrm{Si}}+\pi^{2} \times \frac{D_{\mathrm{Si}}}{z_{\max }^{2}}}$

The integration constant $c$ in Eq. (19) depends on the respective boundary conditions applied at the sediment/water interface. In subtidal areas, a Dirichlet condition is always used, while in intertidal areas the boundary condition changes from a no-flux condition when the flats are exposed at low tide to a Dirichlet condition during inundation. In all instances, a no-flux condition is assumed at $z_{\max }$ :

$\left\{\left.\begin{array}{ll}\left.\frac{\partial C}{\partial z}\right|_{z=0}=0 & \text { for } h=0 \\ C(0)=C_{\text {water }}(t) & \text { for } h>0\end{array} \quad \frac{\partial C}{\partial z}\right|_{z=z_{\max }}=0\right.$

where $h$ is the depth of the overlying water column. When the flats are flooded, the boundary concentration at the sediment/water interface is given by the concentration of dissolved silica in the overlying waters PDSI, i.e. $C_{\text {water }}=$ BDSI $_{\mathrm{sat}}$-PDSI. During flooding, the relaxation of the boundary condition is avoided by specifying an imaginary boundary value $\left(C_{\mathrm{ima}}\right)$ in such a way that the relaxed boundary value matches the actual water column concentration, $C_{\text {water. }}$ Using Eq. (20), one obtains:

$C_{\mathrm{imag}}(0, t)=\frac{C_{\mathrm{water}}(t)-C(0, t-\Delta t) \times e^{-\frac{\Delta t}{t_{a}}}}{\left(1-e^{-\frac{\Delta t}{t_{a}}}\right)}$

The depth integrated dissolution rate, $\bar{P}_{\text {diss }}$, the consumption depth of dissolution, $\mathrm{ID}_{\text {diss }}$, as well as the diffusive flux $\left(F_{\mathrm{Si}}\right)$ are calculated from the transient solution of the dissolved silica profiles. The inverse Bessel function and its respective integrals and deviations are approximated by standard numerical techniques (Press et al., 1992), using a fifthorder approximation of the inverse bessel function (error less than $10^{-10}$ ).

\subsection{Coupled model}

The benthic model described above is coupled to a twodimensional, pelagic, reactive transport model of the Scheldt estuary (Arndt et al., 2007) to assess the importance of benthic processes on the silica dynamics at the system scale. The estuarine hydrodynamics is described using the nested hydrodynamic model MIKE21 NHD (Danish Hydraulic Institute). Three dynamically nested grids form the support of 


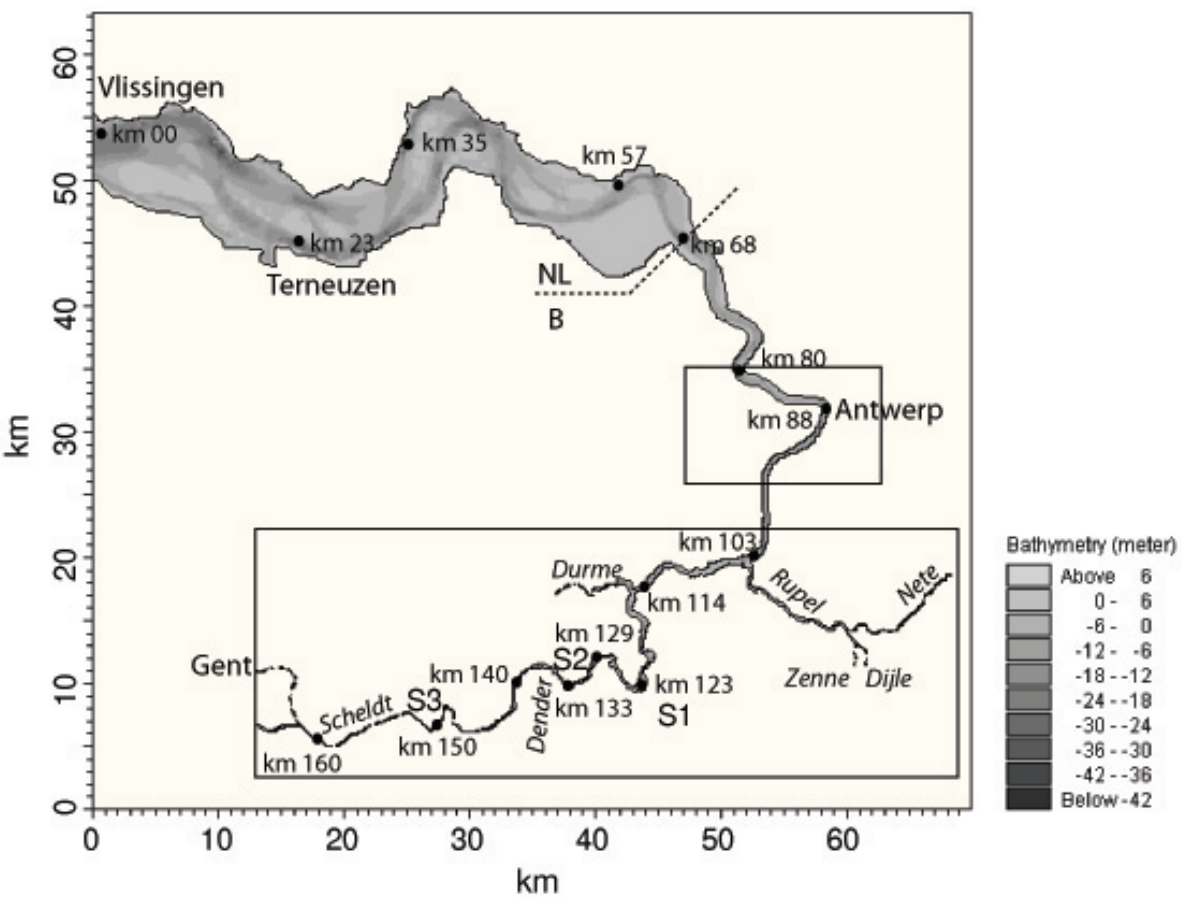

Fig. 1. Map of the Scheldt estuary.

the coupled model, which covers the whole of the Scheldt estuary (Fig. 1).

The spatial resolution is of $33 \times 33 \mathrm{~m}$ for the tidal rivers and the channel bend close to Antwerp, while the saline and brackish estuary is resolved with a space step of $100 \times 100 \mathrm{~m}$. The total number of grid points, for which vertically resolved benthic silica profiles have to be determined, amounts to 56000 .

The representation of coupled reaction and mass transport is based on the vertically-integrated continuity equation for scalar quantities. The benthic and the pelagic biogeochemical models are implemented within the ECOLab environmental modeling tool (Danish Hydraulic Institute). The diatoms in the water column (DIA, mM C) are subject to advection and dispersion, and to a source/sink term, which represents the balance between net growth (NPP, $\mathrm{mM} \mathrm{C} \mathrm{d}^{-1}$ ) and a temperature-dependent, first-order decay term with a mortality rate $k_{\text {mortality }}$ (defined at $10^{\circ} \mathrm{C}$ ) integrating the combined effects of cell lysis and grazing by higher trophic levels:

$$
\begin{aligned}
& \frac{\partial \mathrm{DIA}}{\partial t}+\nabla(\boldsymbol{v D I A})-\nabla(h \times \boldsymbol{D} \boldsymbol{s} \times \nabla \mathrm{DIA}) \\
& =\frac{1}{h}\left(-k_{\text {mortality }} \times f(\text { Temp }) \times \mathrm{DIA}+\mathrm{NPP}\right)
\end{aligned}
$$

where $\boldsymbol{v}$ is the depth-averaged, horizontal velocity vector, $\boldsymbol{D}_{\boldsymbol{s}}$ is the horizontal dispersion coefficient and $f($ Temp $)=\exp (($ Temp -10$) \times \ln (2.075) / 10)$

Net primary production (NPP) is the difference between gross primary production GPP $\left(\mathrm{mMCh}^{-1}\right)$ and the autotrophic algal respiration, which is divided into a biosynthesis term and a maintenance term. Excretion is also considered. Further details about the formulation of the NPP and GPP can be found in Vanderborght et al. (2006) and Arndt et al. (2007). The spatio-temporal evolution of dissolved silica in the water column results from the interaction of transport processes and the consumption of dissolved silica, which is related to the NPP by the $\mathrm{Si}: \mathrm{C}$ ratio:

$$
\begin{aligned}
\frac{\partial \mathrm{PDSI}}{\partial t}+\nabla(\boldsymbol{v P D S I})-\nabla & (h \times \boldsymbol{D} \boldsymbol{s} \times \nabla \mathrm{PDSI}) \\
= & \frac{1}{h}(\mathrm{Si}: \mathrm{C} \times \mathrm{NPP})
\end{aligned}
$$

Pelagic biogenic silica (PBSI) is derived from dead diatoms. It can settle on the estuarine sediments $\left(\bar{P}_{\mathrm{dep}}\right)$ according to:

$\bar{P}_{\text {dep }}=w_{\text {PBSI }} \times p_{\text {dep }} \times \operatorname{PBSI}(t)$

where $w_{\text {PBSI }}$ denotes the sinking velocity of dead diatom cells and $p_{\text {dep }}$ is the probability of deposition. In addition, biogenic silica can reenter the water column by erosion $\left(\bar{P}_{\text {ero }}\right.$, see Eq. (6)), 
Table 1. Parameter values used in the model for primary production and silica consumption. See Vanderborght et al. (2006); Arndt et al. (2007) for parameter values of the complete reaction network.

\begin{tabular}{|c|c|c|}
\hline Symbol & Value & Unit \\
\hline$D_{s}$ & $\begin{array}{l}4 \\
100\end{array}$ & $\begin{array}{l}\mathrm{m}^{2} \mathrm{~s}^{-1} \\
\mathrm{~m}^{2} \mathrm{~s}^{-1}\end{array}$ \\
\hline$k_{\text {mortality }}$ & $6.12 \times 10^{-2}$ & $\mathrm{~d}^{-1}$ \\
\hline Si:C & 0.2 & $\mathrm{~mol} \mathrm{Si} / \mathrm{mol} \mathrm{C}$ \\
\hline$k_{\mathrm{Si}}$ & 0.03 & $d^{-1}$ \\
\hline$D_{\mathrm{Si}}$ & $7 \times 10^{-5}$ & $\mathrm{~m}^{2} \times \mathrm{d}^{-1}$ \\
\hline BDSI $_{\text {sat }}$ & 1000 & $\mu \mathrm{M}$ \\
\hline$\gamma$ & 0.03 & $\mathrm{~m}$ \\
\hline$D_{\text {bio }}$ & $2 \times 10^{-6}$ & $\mathrm{~m}^{2} \mathrm{~d}^{-1}$ \\
\hline$z_{\max }$ & 0.4 & $\mathrm{~m}$ \\
\hline$w_{\text {DIA }}$ & 1.5 & $\mathrm{md}^{-1}$ \\
\hline$\phi$ & 0.7 & - \\
\hline$\rho$ & 2650 & $\mathrm{~kg} \times \mathrm{m}^{-3}$ \\
\hline$M$ & $5.5 \times 10^{-4}$ & $\mathrm{~m} \times \mathrm{d}^{-1}$ \\
\hline$\tau_{\mathrm{crd}}$ & 0.2 & $\mathrm{~N} \times \mathrm{m}^{-2}$ \\
\hline$\rho_{\mathrm{SPM}}$ & 1760 & $\mathrm{~kg} \times \mathrm{m}^{-3}$ \\
\hline$\eta$ & 0.0013 & $\mathrm{~N} \times \mathrm{s} \times \mathrm{m}^{-2}$ \\
\hline$g$ & 9.82 & $\mathrm{~m} \times \mathrm{s}^{-2}$ \\
\hline$\rho_{w}$ & 1000 & $\mathrm{~kg} \times \mathrm{m}^{-3}$ \\
\hline
\end{tabular}

$$
\begin{aligned}
& \frac{\partial \text { PBSI }}{\partial t}+\nabla(\boldsymbol{v} \text { PBSI })-\nabla(h \times \boldsymbol{D} \boldsymbol{s} \times \nabla \text { PBSI }) \\
& =\frac{1}{h}\left(k_{\text {mortality }} \times f(\text { Temp }) \times \text { DIA }-P_{\text {dep }}+P_{\text {ero }}\right)
\end{aligned}
$$

The coupled model includes a fully-formulated SPM transport model. The erosion and deposition fluxes are expressed according to the formulations of Ariathurai (1974), Partheniades (1962) and Einstein and Krone (1962):

$$
\begin{array}{r}
\frac{\partial \mathrm{SPM}}{\partial t}+\nabla(\boldsymbol{v S P M})-\nabla \\
(h \times \boldsymbol{D} \boldsymbol{s} \times \nabla \mathrm{SPM}) \\
=\frac{1}{h}\left(R_{\text {ero }}-R_{\mathrm{dep}}\right)
\end{array}
$$

where

$R_{\text {ero }}=p_{\text {ero }} \times M \times \mathrm{SPM}_{b}$

$R_{\mathrm{dep}}=p_{\mathrm{dep}} \times w_{s} \times \mathrm{SPM}$

In Eqs. (29) and (30) $p_{\text {ero }}$ and $p_{\text {dep }}$ stand for the probabilities for erosion and deposition, respectively, $M$ denotes the erosion constant $(\mathrm{m} / \mathrm{s}), w_{s}$ represents the settling velocity of particles $(\mathrm{m} / \mathrm{s})$ and $\mathrm{SPM}_{b}$ refers to the concentration of total solids in the sediment. The settling velocity $w_{s}$ depends directly on the diameter of suspended particles. The dynamical adaption of the SPM diameter to processes such as deposition and erosion is described by using the effective variable approach proposed by Wirtz and Eckhardt (1996) and Wirtz (1997). The source/sink terms in the continuity equation are numerically integrated using the Euler method (e.g. Press et al., 1992) with a time step of $\Delta t=200 \mathrm{~s}$, while the advection-dispersion terms are solved with the third order finite difference scheme QUICKEST (Ekebjaerg and Justesen, 1991). Parameter values for the reaction network are given in Table 1. Most of the model parameters are constrained by insitu measurements in the Scheldt estuary. Observed dissolution rate constants vary between 0.02 and $0.05 \mathrm{~d}^{-1}$ (Roubaix, pers. communication). We adopt a maximum rate constant $\max k_{\mathrm{Si}}$ of $0.03 \mathrm{~d}^{-1}$ for the coupled model. The transport of solutes through the sediment-water interface can be enhanced by current/wave action, bioirrigation and bioturbation. The apparent diffusion coefficient accounts implicitly for these effects and is therefore higher than the pure molecular diffusion coefficient $\left(D_{\mathrm{Si}}=35 \times 10^{-6} \mathrm{~m}^{2} \times \mathrm{d}^{-1}, \mathrm{Li}\right.$ and Gregory (1974)). Measurements of dissolved silica profiles in the Scheldt estuary show that porewater concentrations can reach equilibrium with respect to opaline silica. We therefore apply a BDSI $\mathrm{sat}_{\text {of }} 1000 \mu \mathrm{M}$. A full description of the hydrodynamic, the SPM and the pelagic biogeochemical model, including the details of numerical integration and model calibration can be found in Arndt et al. (2007).

\section{Results and discussion}

\subsection{Baseline simulation and sensitivity analysis}

The sensitivity of model outputs to variations in benthic model parameters and forcing conditions is investigated by forcing the benthic model with idealized boundary conditions at the sediment water interface (Fig. 2). A summer diatom bloom is initiated at the beginning of the simulation (June) and is represented by a Gauss curve. It is assumed that maximum PBSI are reached in August, when temperature, light and discharge conditions are most favorable (Arndt et al., 2007). A depletion of PDSI coincides with the bloom and follows a negative Gauss peak according to:

$$
\begin{aligned}
& \text { PBSI }=h_{\mathrm{PBSI}} \times \exp \left(-\frac{(t-61)^{2}}{w_{\mathrm{PBSI}}}\right) \\
& \text { PDSI }=\operatorname{MAX}\left(0, l_{\mathrm{PDSI}}-h_{\mathrm{PDSI}} \times \exp \left(-\frac{(t-61)^{2}}{w_{\mathrm{PDSI}}}\right)\right)
\end{aligned}
$$

The height of the two Gauss peaks, $h_{\mathrm{PBSI}}$ and $h_{\mathrm{PDSi}}$, their widths, $w_{\text {PBSI }}$ and $w_{\text {PDSI }}$, as well as the background level of dissolved silica, $l_{\mathrm{PDSI}}$, determine the magnitudes and durations of the bloom and associated silica depletion. The ambient water temperature is also changing over a seasonal cycle 
(Fig. 2b). The imposed deposition and erosion fluxes of SPM show a typical variation on a tidal time scale (Fig. 2c).

\subsubsection{Baseline simulation}

The baseline simulation is run with the set of baseline parameters given in Table 2. Figure 3 illustrates the temporal evolution of the benthic silica dynamics over a period of one year, starting from June. Benthic fluxes respond rapidly to the deposition pulse during the pelagic summer bloom $\left(P_{\mathrm{dep}}\right.$, Fig. 3a).

The increasing deposition flux of PBSI leads to a gradual increase of $\overline{\mathrm{BBSI}}$ (Fig. 3c). The dissolution of the biogenic silica results in a build up of the depth-integrated dissolved silica concentration BDSI (Fig. 3d) that sustains a diffusive return flux ( $\left.F_{\text {diff }}\right)$ to the water column (Fig. 3b). The temporal evolution of the net rates (Fig. 3a, b) is characterized by two different periods. The first period (day 0-100) is coupled to the productive period and is characterized by positive net rates. The deposition flux exceeds the loss due to dissolution, erosion and burial and $\overline{\mathrm{BBSI}}$ accumulates in the sediment (Fig. 3a, c). It reaches its maximum concentration at the end of the productive period. During this time, the increasing $\overline{\mathrm{BBSI}}$ content sustains a rapid increase in dissolution rate, diffusive flux (Fig. 3b) and $\overline{\mathrm{BDSI}}$ concentration (Fig. 3d). The increase in silica dissolution is enhanced by the depletion of PDSI, which triggers a high diffusive transport of $\overline{\mathrm{BDSI}}$ through the sediment water interface and therefore, maintains undersaturation of interstitial waters. Maximum dissolution rates are reached in mid August, shortly after the maximum deposition flux, when the $\overline{\mathrm{BBSI}}$ in the uppermost centimeters is highest and interstitial waters are highly undersaturated. In late August, a maximum in diffusive flux is reached due to the combined influence of ongoing PDSI depletion and high $\overline{\mathrm{BDSI}}$ concentration.

The decline of the summer bloom triggers the beginning of the second period (day 100-365), which is characterized by negative net rates. The decrease in the deposition flux in combination with an increase in the erosion flux and increasing saturation of interstitial waters which leads to a subsequent decrease in dissolution rates (Fig. 3a). Yet, the decreasing dissolution rate now exceeds the strongly reduced deposition flux, and $\overline{\mathrm{BBSI}}$ is progressively consumed during the winter months (Fig. 3a, c). On the other hand, the dissolution of $\overline{\mathrm{BBSI}}$ is too weak to compensate the diffusive loss to the overlying water and therefore, the concentration of $\overline{\mathrm{BDSI}}$ decreases (Fig. 3b, d).

\subsubsection{Sensitivity to internal benthic model parameters}

Figure 4 illustrates the distribution of the maximum $\overline{\mathrm{BBSI}}$ content (Fig. 4a), the time- and depth-integrated dissolution rate of $\overline{\text { BBSI, }} \int \bar{P}_{\text {diss }}$ (Fig. 4b), the preservation efficiency after one year of simulation (Fig. 4c), the depth-integrated concentration of $\overline{\mathrm{BDSI}}$ after one year of simulation (Fig. 4d), and
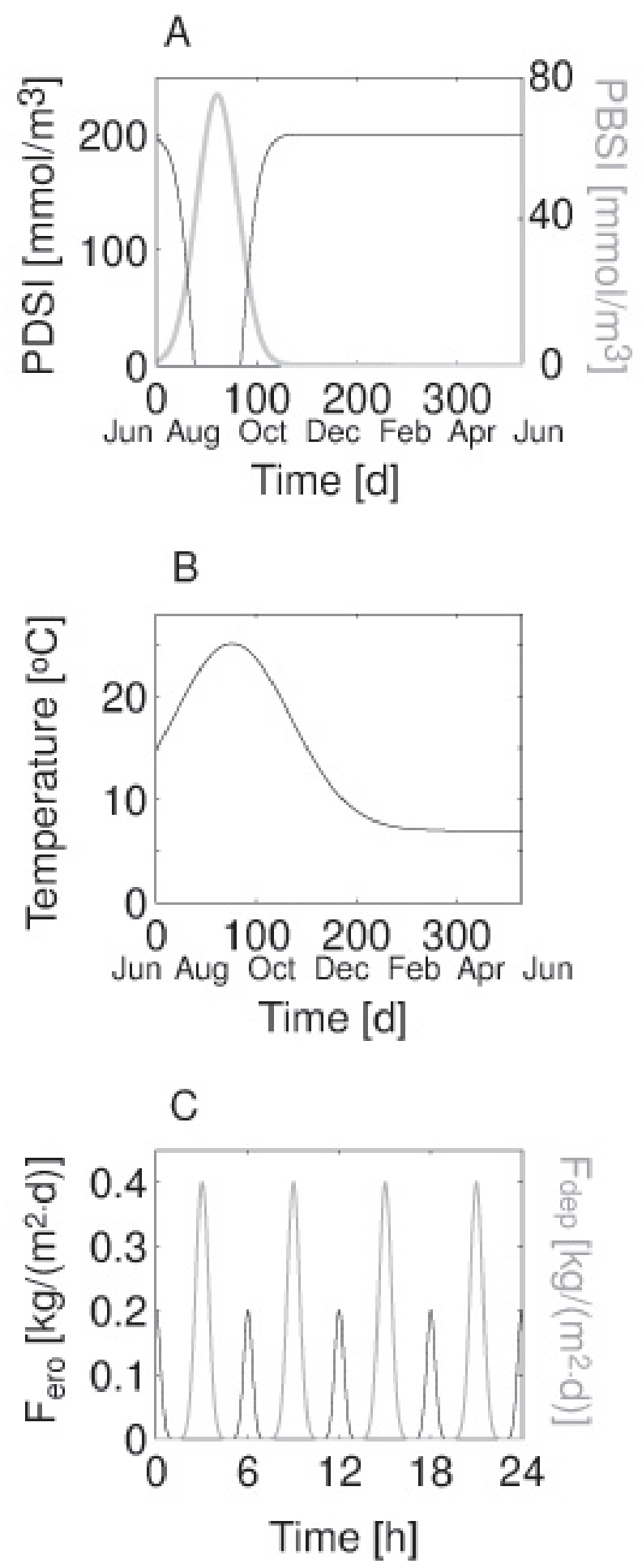

Fig. 2. Idealized boundary conditions used in the sensitivity analysis of the benthic model. (A) Biogenic silica (PBSI) and dissolved silica (PDSI) concentrations in the water column, (B) temperature and $(\mathbf{C})$ erosion $\left(F_{\text {ero }}\right)$ and deposition $\left(F_{\text {dep }}\right)$ flux of suspended matter. 
Table 2. Parameter sets used in model simulations.

\begin{tabular}{ll|llll}
\hline Symbol & Unit & Baseline & $\begin{array}{l}\text { Sensitivity Experiment } \\
\text { I }\end{array}$ & II & III \\
\hline$k_{\mathrm{Si}}$ & $\mathrm{d}^{-1}$ & 0.03 & {$[0.006-0.36]$} & {$[0.005-0.1]$} & $0.01,0.05$ \\
$D_{\mathrm{Si}}$ & $\mathrm{m}^{2} \mathrm{~d}^{-1}$ & $7 \times 10^{-5}$ & {$\left[3 \times 10^{-5}-3 \times 10^{-4}\right]$} & $7 \times 10^{-5}$ & {$\left[3 \times 10^{-5}-3 \times 10^{-4}\right]$} \\
$\mathrm{BDSI}_{\mathrm{Sat}}$ & $\mu \mathrm{M}$ & 1000 & {$[600-1000]$} & 1000 & 1000 \\
$\gamma$ & $\mathrm{m}$ & 0.03 & {$[0.01-0.05]$} & {$[0.01-0.05]$} & {$[0.01-0.05]$} \\
$D_{\text {bio }}$ & $\mathrm{m}^{2} \mathrm{~d}^{-1}$ & $2 \times 10^{-6}$ & {$\left[1 \times 10^{-6}-5 \times 10^{-5}\right]$} & {$\left[1 \times 10^{-6}-5 \times 10^{-5}\right]$} & {$\left[1 \times 10^{-6}-5 \times 10^{-5}\right]$} \\
$w_{\text {SSI }}$ & $\mathrm{d}$ & 61 & 61 & {$[30-93]$} & {$[30-93]$} \\
$w_{\text {PDSI }}$ & $\mathrm{d}$ & 61 & 61 & 61 & 61 \\
$h_{\text {SSI }}$ & $\mu \mathrm{M}$ & 80 & 80 & 80 & 80 \\
$h_{\text {DSI }}$ & $\mu \mathrm{M}$ & 400 & 400 & 400 & 400 \\
$l_{\text {DSI }}$ & $\mu \mathrm{M}$ & 200 & 200 & 200 & 200 \\
$z_{\text {max }}$ & $\mathrm{m}$ & 0.3 & 0.3 & 0.3 & 0.3 \\
\hline
\end{tabular}
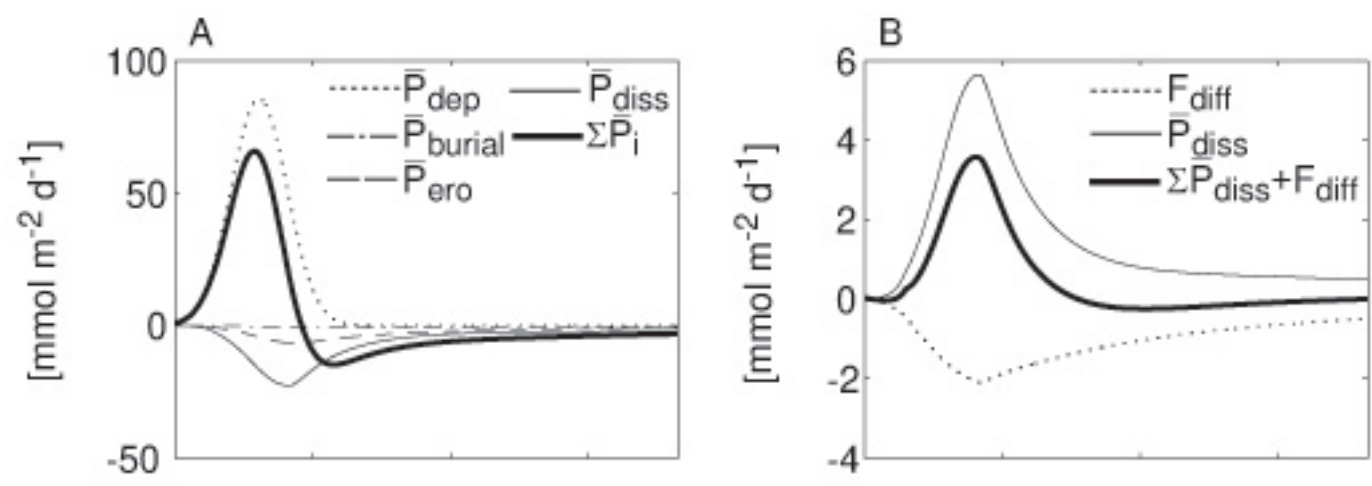

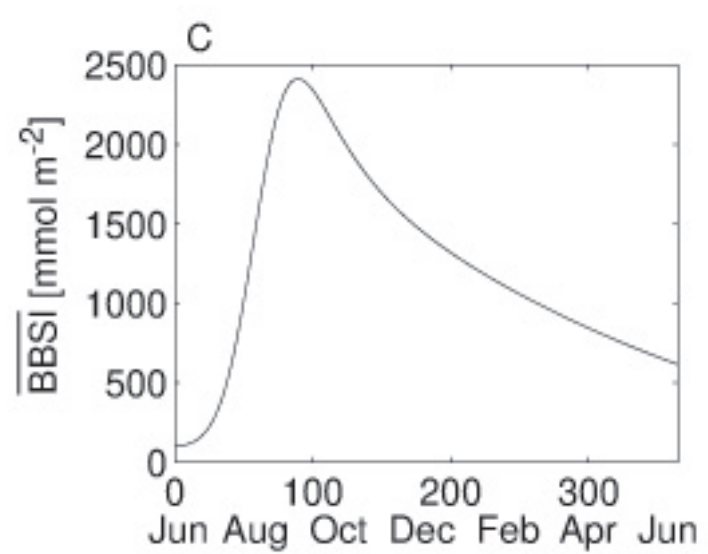

Time [d]

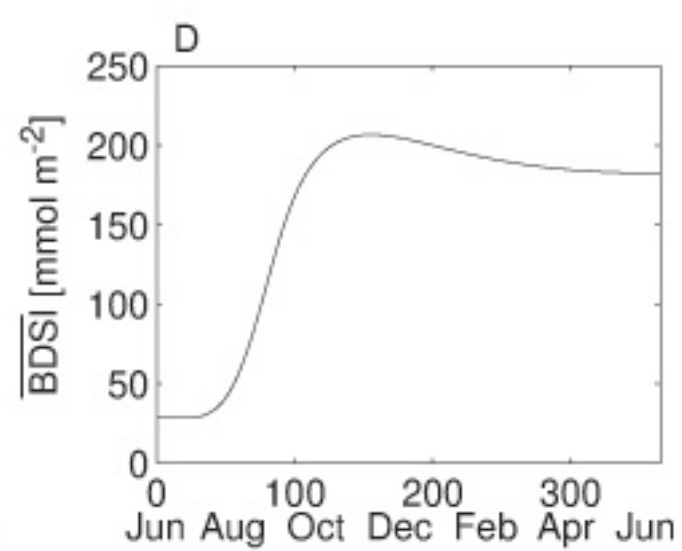

Time [d]

Fig. 3. Temporal evolution of depth-integrated (A) deposition flux $\overline{P_{\text {dep }}}$, erosion flux $\overline{P_{\text {ero }}}$, burial flux $\overline{P_{\text {burial }}}$, dissolution rate of biogenic silica $\overline{P_{\text {diss }}}$ and net rate $\sum_{i} \overline{P_{i}},(\mathbf{B})$ depth-integrated dissolution rate $\overline{P_{\text {diss }}}$, diffusive flux $F_{\text {diff }}$, and net rate $\sum \overline{P_{\text {diss }}}-F_{\text {diff }}(\mathbf{C})$ depthintegrated biogenic silica content in the sediments $\overline{\mathrm{BBSI}}$ and (D) depth-integrated dissolved silica concentration $\overline{\mathrm{BDSI}}$. Simulation results correspond to the baseline parameter set (Table 2)

the time-integrated diffusive flux $\int F_{\text {diff }}$ of BDSI (Fig. 4e, f) over a typical range of maximum dissolution rate constants, $\max k_{\mathrm{Si}}$ (Ruardij and Van Raaphorst, 1995). The mean value of 1000 randomly drawn parameter vectors ( for parameter ranges see Table 2 , sensitivity internal parameters) for a common $\max k_{\mathrm{Si}}$ is indicated by the solid line. Most of the vari- 

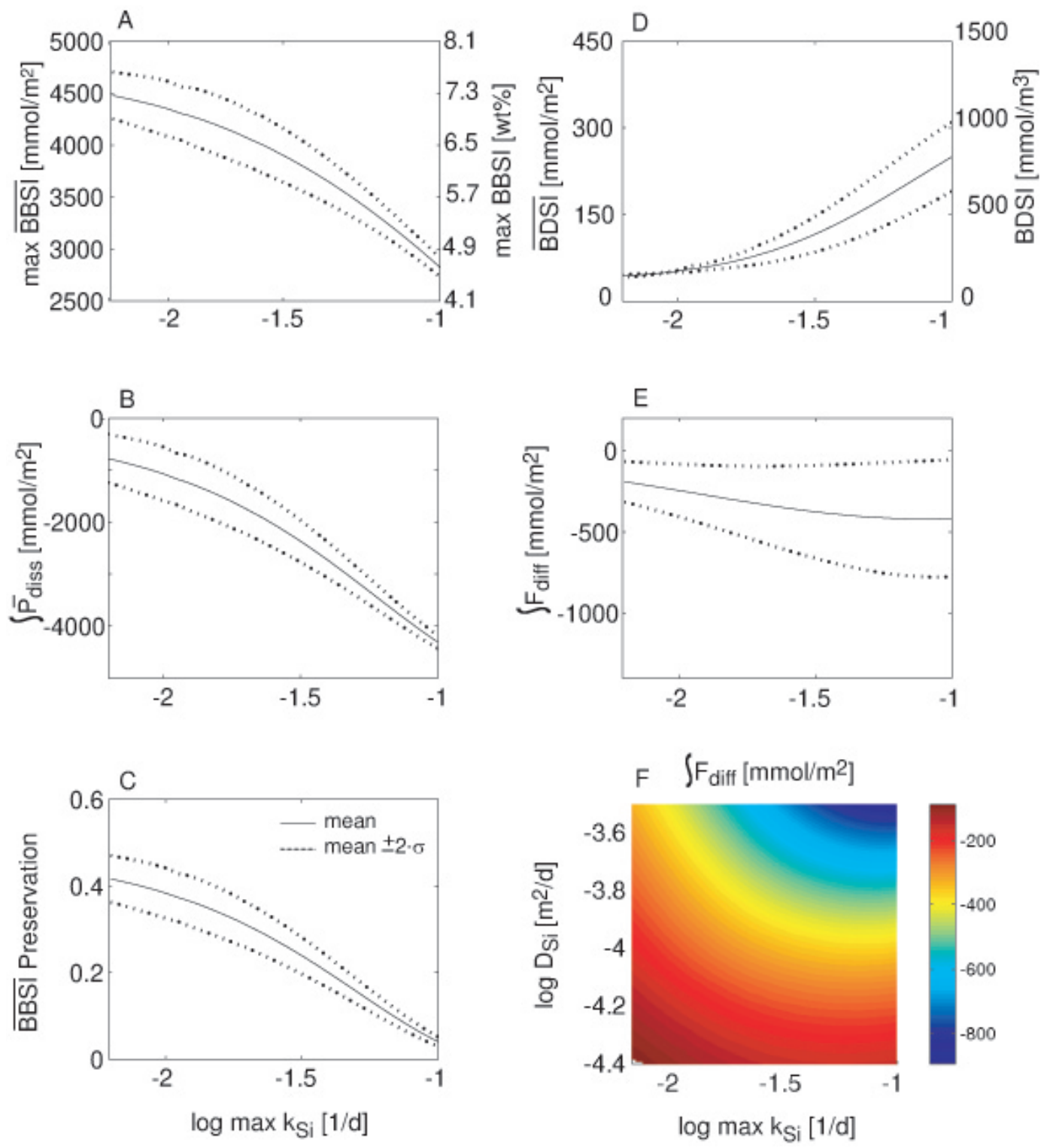

Fig. 4. Distribution of benthic variables and processes over the logarithm of maximum dissolution rate constants max $k_{\mathrm{Si}}$. (A) Annual maximum, depth-integrated biogenic silica contents max $\overline{\mathrm{BBSI}}(\mathbf{B})$ time- and depth integrated dissolution rates $\int \bar{P}_{\text {diss }}$, (C) preservation of $\overline{\mathrm{BBSI}}$ after one year of simulation, (D) average BDSI and depth-integrated $\overline{\mathrm{BDSI}}$ dissolved silica concentration at the end of simulation and (E) time-integrated diffusive fluxes $\int F_{\text {diff. }}$ (F) Distribution of time-integrated diffusive fluxes over maximum dissolution rates $k_{\text {Si }}$ and diffusion coefficients $D_{\mathrm{Si}}$. Shown are the results of 1000 model runs with randomly drawn parameter vectors (Table 2, Sensitivity experiment I).

ation observed in the parameter space falls in the area within two standard deviations away from the mean value. According to the Tchebychev inequality, this area comprises at least $75 \%$ of the values of any population.

In general, $\int \bar{P}_{\text {diss }}$ increases with increasing max $k_{\mathrm{Si}}$. The enhanced dissolution promotes a decrease in maximum $\overline{\mathrm{BBSI}}$ contents and preservation efficiency. While ca. $40 \%$ of the deposited $\overline{\text { BBSI }}$ is preserved for $\max k_{\mathrm{Si}}<10^{-2} \mathrm{~d}^{-1}$, the preservation efficiency rapidly decreases with increasing re- activities and reaches values close to $0 \%$ in the upper parameter range (Fig. 4c). The dissolution leads to a build up of BDSI and the time-integrated diffusive flux therefore increases with increasing reactivities (Fig. 4d, e). In the upper parameter space, the depth-averaged concentration BDSI after one year of simulation approaches the saturation value $\left(800 \mathrm{mmol} \mathrm{m}^{-3}\right)$, while it drops to the water column concentrations $\left(200 \mathrm{mmol} \mathrm{m}^{-3}\right)$ in the lower parameter range (Fig. 4d). 
In the area of high reactivities $\left(\max k_{\mathrm{Si}}>0.03 \mathrm{~d}^{-1}\right)$, $\int \bar{P}_{\text {diss }}$, the preservation efficiency and the maximum $\overline{\mathrm{BBSI}}$ reveal relatively low standard deviations. In this area, the model outputs are thus mainly determined by the reactivity of the deposited material. However, if reactivities are low, the standard deviation increases, indicating the importance of other parameters (Fig. 4a-c). Diffusion coefficients become more important in the area of decreasing $\max k_{\mathrm{Si}}$ since they control the saturation state of the interstitial waters. High diffusion coefficients lead to an enhanced diffusive transport of BDSI out of the sediment, to a low interstitial water saturation and, thus, to increasing $\int \bar{P}_{\text {diss }}$. Low diffusion coefficients, however, maintain relatively high BDSI and slow down dissolution. The sensitivity of model outputs to the diffusion coefficients decreases with increasing reactivities, because the high dissolution rates keep the porewaters close to saturation. $\int F_{\text {diff }}$ reveals, however, a different pattern with high standard deviations throughout the whole range of rate constants (Fig. 4e). The combined influence of max $k_{\mathrm{Si}}$ and $D_{\mathrm{Si}}$ on $\int F_{\text {diff }}$ is shown in Fig. 4f. Standard deviations are highest in the region of high reactivities (Fig. 4e), where the $\int F_{\text {diff }}$ are not limited by the availability of BDSI, which is constantly replenished by high dissolution rates (Fig. 4b). In this case, the magnitude of the $\int F_{\text {diff }}$ rapidly increases with increasing $D_{\mathrm{Si}}$ (Fig. 4f). The sensitivity of $\int F_{\text {diff }}$ to $D_{\mathrm{Si}}$ decreases with decreasing reactivities, as indicated by both lower standard deviations (Fig. 4e) and smaller gradients in the parameter space (Fig. $4 \mathrm{f}$ ). In this region, $\int F_{\text {diff }}$ is slowed down by relatively low BDSI concentrations, leading to a reduced concentration gradient at the sediment/water interface.

\subsubsection{Time lags and sensitivity to forcing conditions}

The benthic flux response to the pulsed deposition flux of biogenic silica which is triggered by the pelagic summer bloom is driven by a combination of water column conditions and benthic processes. The mean time delays, evaluated from 1000 simulations with randomly drawn parameter vectors (parameter ranges see Table 2, Sensitivity experiment I) provide further insights into the sensitivity of the benthic flux response to internal model parameters (Fig. 5a i-c i). Furthermore, the influence of pelagic silica concentrations on the benthic response are assessed on the basis of 500 simulations with randomly drawn values for $w_{\text {PDSI }}$ (Fig. 5a ii-c ii, a iii-c iii). To evaluate the combined effect of simultaneously varying benthic processes and pelagic concentrations, these 500 simulations are repeated with seven different systematically chosen $\max k_{\mathrm{Si}}$ (parameter ranges see Table 2, Sensitivity experiment II) as well as a combination of three different $D_{\mathrm{Si}}$ values (parameter ranges see Table 2, Sensitivity experiment III).

In general, low reactivities $\left(\max k_{\mathrm{Si}}<0.01 \mathrm{~d}^{-1}\right)$ constrain the intensity of the benthic pelagic coupling and result in a slow benthic response. The time when the maximum diffusive flux occurs $\left(t_{\max }\right)$ is hardly influenced by the much shorter period of silica depletion in the water column, and it is reached significantly later in the year $(\Delta t=120 \mathrm{~d}$ for $\max k_{\mathrm{Si}}=0.005 \mathrm{~d}^{-1}$, see also Fig. 5a i) when PDSI is back to $200 \mu \mathrm{M}$ (Fig. 2). Thus, the sensitivity of the flux response to changes in overlying water concentrations is weak (Fig. 5a ii). However, the distribution of time delays in the area of low reactivities is characterized by high standard deviations, and time delays vary by almost two months (Fig. 5a i). In this area of the parameter space, high $D_{\mathrm{Si}}$ lead to a tighter benthic pelagic coupling and therefore smaller time delays, as well as a higher sensitivity to variations in $w_{\text {PDSI }}$ (Fig. $5 \mathrm{a}$ iii). On the other hand, low values of $D_{\mathrm{Si}}$ slow down the coupling and delay the response by up to two months compared to high values of $D_{\mathrm{Si}}$. High reactivities ( $\left.\max k_{\mathrm{Si}}>0.08 \mathrm{~d}^{-1}\right)$ result in a tight benthic-pelagic coupling, characterized by a fast diffusive response (Fig. 5a i). The benthic response is completely controlled by the conditions in the water column, as indicated by the nearly constant time lag and extremely low standard deviations (Fig. 5a i). Variations in $D_{\mathrm{Si}}$ have thus little influence on benthic dynamics in this area of the parameter space. $F_{\text {diff }}$ quickly responds to a decrease in PDSI concentrations and coincide with the end of the depletion period. The time lag therefore increases linearly with increasing $w_{\text {PDSI }}$ (Fig. 5a ii) and corresponds to the end of the depletion period. However, the timing of the diffusive flux response to $w_{\text {PDSI }}$ reveals a more complex pattern in the area of intermediate reactivities (Fig. 5a ii). Short depletion periods $\left(w_{\mathrm{PDSI}}<50 \mathrm{~d}\right)$ do not exert any significant influence on the timing of maximum diffusive fluxes. However, if the water column depletion persists long enough, it becomes progressively more important, time lags become shorter and eventually move closer to the end of the depletion period. This leads to a sudden drop of the time lags for intermediate $w_{\text {PDSI }}$ by almost three weeks. The threshold value and the smoothness of the transition generally increases with decreasing $\max k_{\mathrm{Si}}$. A similar pattern can also be observed for low reactivities, when the benthic pelagic coupling becomes tighter with increasing $D_{\text {Si }}$ (Fig. 5a iii).

The timing of max $\bar{P}_{\text {diss }}$ is mainly controlled by $\bar{P}_{\mathrm{dep}}$, with maximum rates reached within a month after the maximum in $\bar{P}_{\text {dep }}$. The time difference between these two events shows a low variability $(<5 \mathrm{~d})$ over the parameter range of $\max k_{\mathrm{Si}}$ (Fig. 5b i). High reactivities $\left(\max k_{\mathrm{Si}}>0.08 \mathrm{~d}^{-1}\right.$ ) result in fast dissolution rates and $t$ max $P_{\text {diss }}$ coincides with the end of the depletion period in the lower range of $w_{\text {PDSI }}$ (Fig. $5 \mathrm{~b}$ ii). However, if the depletion period exceeds a certain threshold value, the temporal dynamics of dissolution rates is entirely controlled by the reaction kinetics and the time lag does not further increase with increasing depletion periods (Fig. 5b ii). The respective threshold value, as well as the value of the plateau where the time lags are constant depend mainly on $\max k_{\mathrm{Si}}$ and increases with decreasing reactivities. Low reactivities lead to a slow response and are again more sensitive to variations in $D_{\mathrm{Si}}$, indicated by higher standard deviations in this area of the parameter space (Fig. $5 b \mathrm{i}$, iii). 

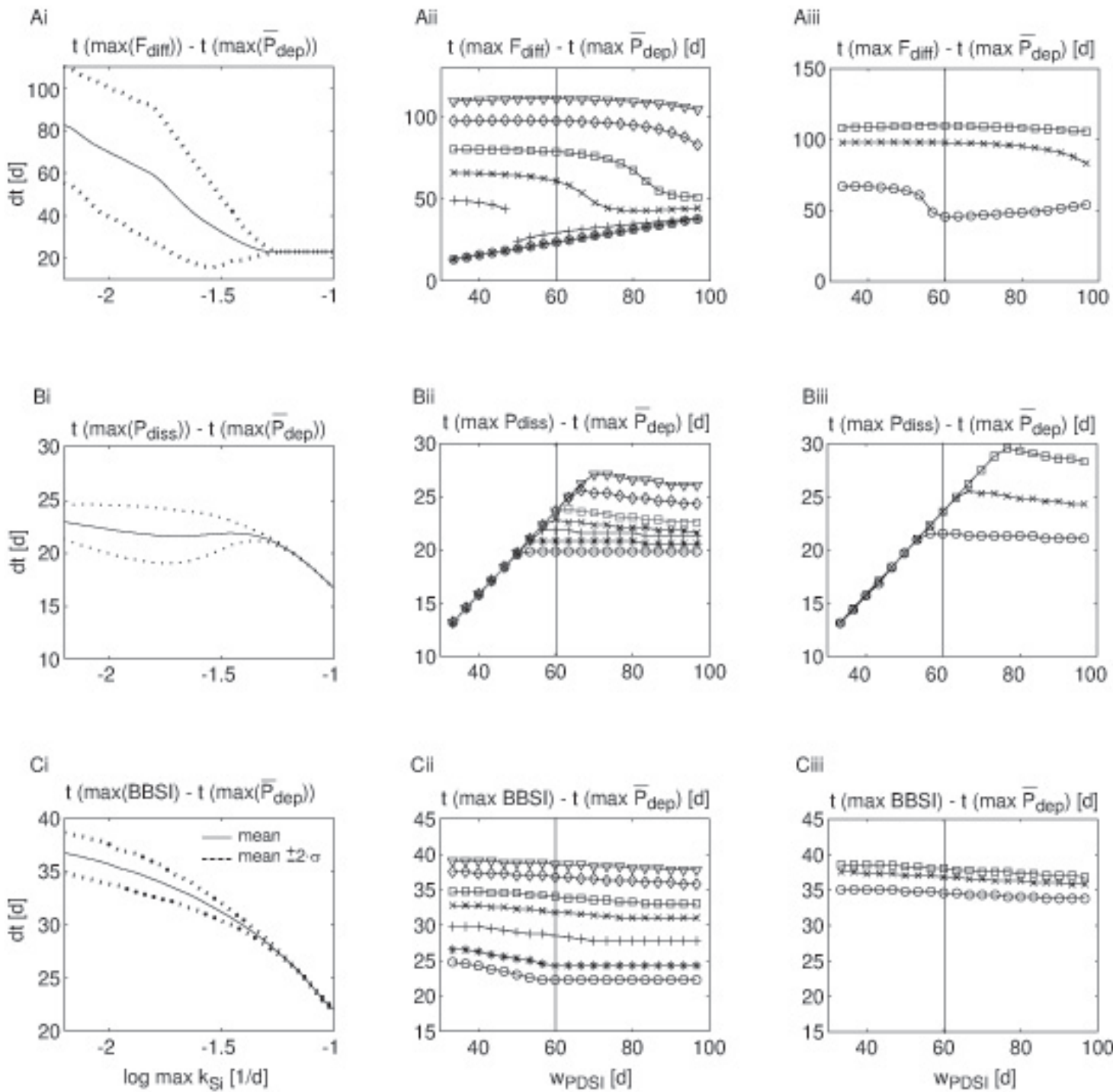

Cii
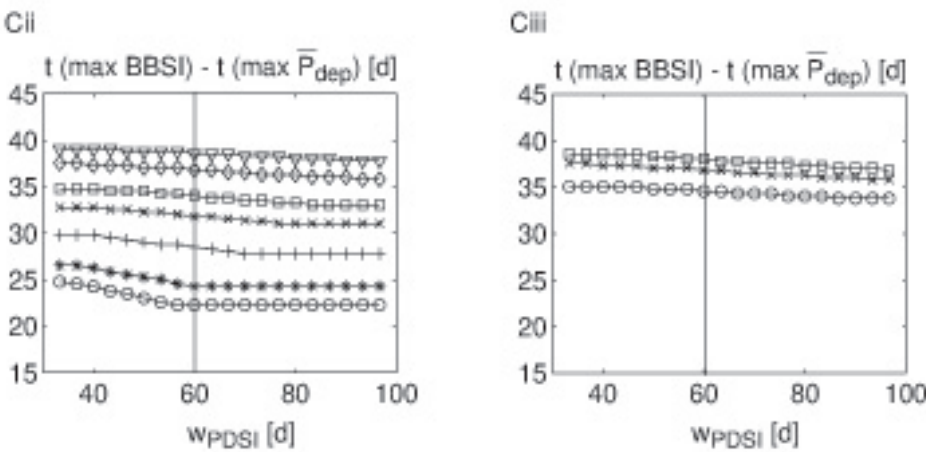

$$
\begin{aligned}
D_{S i} \in & {\left[0.000035 m^{2} d^{-1}\right.} \\
& \left.-0.00035 m^{2} d^{-1}\right]
\end{aligned}
$$

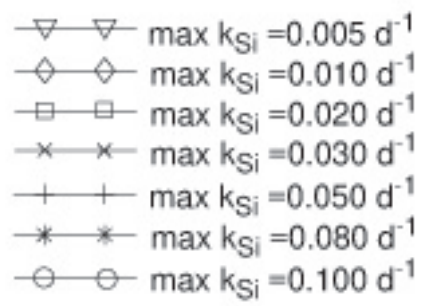$$
\begin{aligned}
& \square \square D_{S i}=0.000035 \mathrm{~m}^{2} \mathrm{~d}^{-1} \\
& \times \times-D_{S i}=0.000070 \mathrm{~m}^{2} \mathrm{~d}^{-1} \\
& -\triangle D_{\mathrm{Si}}=0.000350 \mathrm{~m}^{2} \mathrm{~d}^{-1}
\end{aligned}
$$

Fig. 5. Distribution of time lags between (A) maximum diffusive flux $t$ (max $F_{\text {diff }}$ ) and maximum deposition rate $t$ (max $\bar{P}_{\text {dep }}$ ), (B) time lag between maximum dissolution rate $t\left(\max \bar{P}_{\text {diss }}\right)$ and maximum deposition rate $t\left(\max \bar{P}_{\text {dep }}\right)$ and (C) time lag between maximum $\overline{\text { BBSI }}$ content $t(\max \overline{\mathrm{BBSI}})$ and and maximum deposition rate $t\left(\max \bar{P}_{\text {dep }}\right)$ over the i) logarithm of maximum dissolution rate constants, ii) and iii) different length of the silica depletion in the water column $w_{\text {PDSI }}$. Shown are the results of i) 1000 model runs with randomly drawn parameter vectors (Table 2 Sensitivity I), ii) 500 randomly drawn $w_{\text {PDSI }}$ and 7 different max $k_{\text {Si }}$ (Table 2 II) and iii) 500 randomly drawn $w_{\text {PDSI }}$ and three different $D_{\mathrm{Si}}$ (Table 2 III). The $w_{\text {PDSI }}$ used in the first sensitivity experiment (i) is indicated in ii) and iii) by a solid line. 
The time lags between max $\bar{P}_{\text {dep }}$ and $t$ max $\overline{\mathrm{BBSI}}$ are shown in Fig. $5 \mathrm{c}$ i. In general, maximum $\overline{\mathrm{BBSI}}$ are reached shortly before the $\bar{P}_{\text {diss }}$ starts to exceed $\bar{P}_{\text {dep }}$. For high reactivities, maximum contents are reached shortly after the $\bar{P}_{\text {dep }}$ peak, while decreasing reactivities, lead to longer delays. In the lower range of the parameter space, the maximum $\overline{\mathrm{BBSI}}$ content is mainly sensitive to variations in $\max k_{\mathrm{Si}}$. Yet, sensitivity to variations in $D_{\mathrm{Si}}$ increases with decreasing $\max k_{\mathrm{Si}}$ (Fig. 5c i). If $D_{\mathrm{Si}}$ is low and $\bar{P}_{\text {diss }}$ is further slowed down by near saturation conditions, $\bar{P}_{\text {diss }}$ never exceeds $\bar{P}_{\text {dep }}$ during the bloom period and maximum $\overline{\mathrm{BBSI}}$ contents are reached at the end of the growth season ( $>30 \mathrm{~d}, \mathrm{Fig} .5 \mathrm{c}$ i). An enhanced $F_{\text {diff }}$ promotes lower saturation and thus a higher $\bar{P}_{\text {diss }}$. In this case, maximum $\overline{\mathrm{BBSI}}$ contents are reached earlier (2030d). The duration of the depletion period has very little influence on the time lag between maximum $\bar{P}_{\text {dep }}$ and maximum $\overline{\mathrm{BBSI}}$ contents (Fig. $5 \mathrm{c}$ ii, iii). Increasing $w_{\text {PDSI }}$ leads to a shift of merely two days, in contrast to the much larger shift of almost three weeks, which is triggered by decreasing $\max k_{\mathrm{Si}}$ (Fig. $5 \mathrm{c}$ ii). Maximum $\overline{\mathrm{BBSI}}$ contents are reached just before $\bar{P}_{\text {diss }}$ starts to exceed $\bar{P}_{\text {dep }}$.

\subsection{System scale simulation}

\subsubsection{The Western Scheldt}

The river Scheldt originates in France and flows $355 \mathrm{~km}$ through France, Belgium and the Netherlands before discharging into the North Sea near Vlissingen (The Netherlands). The part of the river influenced by the tide is referred to as the Scheldt Estuary (Fig. 1) and comprises the saline (salinity=30-10) Western Scheldt from the estuarine mouth to the Dutch/Belgian border ( $\mathrm{km} \mathrm{68)}$ ) followed by the brackish estuary (salinity $=10-1$ ), and further upstream by the tidal, freshwater river system. In the saline part, the estuary consists of a complex network of flood channels and a continuous ebb channel which are intercepted by extensive intertidal flats and surrounded by wetlands (Jeuken, 2000; Winterwerp et al., 2001). Close to the Dutch/Belgian border, this complex network reduces to a single, well-defined channel with much smaller intertidal areas.

The tidal wave is semidiurnal and propagates within a complex network of tributaries (Dijle, Zenne, Kleine Nete,

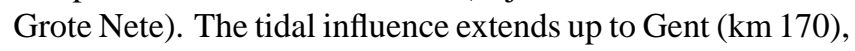
where the wave is blocked by the presence of weirs. The significant dominance of the tidal prism $\left(2 \times 10^{9} \mathrm{~m}^{3}\right.$ per tidal cycle) over the mean freshwater discharge $\left(5 \times 10^{6} \mathrm{~m}^{3}\right.$ per tidal cycle) leads to a vertically well mixed system with small salinity stratification $(<1)$. Along the estuarine gradient, salinity decreases upstream and drops to values below 1 in the vicinity of the confluence with the Rupel (km 103). However, the salinity intrusion is strongly dependent on the freshwater discharge, the phase of the tide and the history of the hydraulic regime and may migrate over a distance of $40 \mathrm{~km}$ (Baeyens et al., 1998). The dominant tidal influence causes long residence times of 50 to 70 days for dissolved species in the Western Scheldt (Soetaert and Herman, 1995b). The Scheldt is a relatively turbid estuary and SPM concentrations can reach maximum values up to $400 \mathrm{mg}^{-1}$. SPM concentrations reveal large longitudinal gradients (Baeyens et al., 1998; Villars and Vos, 1999; Chen et al., 2005), while vertical SPM gradients are generally small (Villars and Vos, 1999; Chen et al., 2005).

\subsubsection{Pelagic silica dynamics in the Scheldt estuary}

Monthly monitoring programmes reveal the development of a small riverine spring phytoplankton bloom and a more intense estuarine summer diatom bloom in the freshwater tidal reaches of the Scheldt (Meire et al., 2005; Muylaert et al., 2005). Arndt et al. (2007) showed that primary production dynamics are mainly linked to variabilities in the physical forcing conditions. They showed that monthly observations of diatom carbon and PDSI in summer 2003 reveal a characteristic spatial pattern which is well captured by the pelagic model. During a seasonal cycle, diatom biomass reaches maximum values of 200-1200 $\mu \mathrm{MC}$ in the upstream reaches of the Scheldt river ( $>\mathrm{km} \mathrm{100)}$ where shallow water depths (average $h=2.6 \mathrm{~m}$ ), low turbidities $(<50-100 \mathrm{mg} / \mathrm{l})$ and a constant riverine supply of PDSI create a favorable environment for diatom growth. Within this zone, the area around $\mathrm{km} 120$ provides the most favorable physical conditions for diatom growth (balance point with lowest total energy dissipation and, thus, low SPM concentrations). Downstream of km 100, diatom carbon concentrations abruptly decrease as a consequence of the rapid increase in SPM concentrations, from $<50 \mathrm{mg} \mathrm{l}^{-1}$ around $\mathrm{km} 120$ to $60-340 \mathrm{mg} / \mathrm{l}$ in the estuarine turbidity maximum between $\mathrm{km} 80$ and $\mathrm{km} 114$. Despite local shallow water depths, these high SPM concentrations result in a strong light-limitation of photosynthesis. Downstream of the turbidity maximum, the widening and deepening of the estuary leads to dilution. Besides, the increase in water depth result in a negative net phytoplankton growth (Desmit et al., 2005) and thus maintains low diatom biomass $(<200 \mu \mathrm{MC})$. Weekly PDSI measurements indicate that during most of the simulation period, the Scheldt river and its tributaries provide an almost constant supply of PDSI to the tidal river-estuarine continuum. This riverine silica input is mostly consumed in the upstream zones of the Scheldt, where gross primary production reaches maximum values (Fig. 6). Low river discharge generally improves the growth conditions. Yet, it also induces a progressive silica limitation which ultimately leads to an upstream shift of the area of maximum primary production away from the balance point (Fig. 6). During dry years, such as 2003, a complete consumption of PDSI can occur over the whole area of the freshwater tidal reaches. In autumn, primary production rapidly 

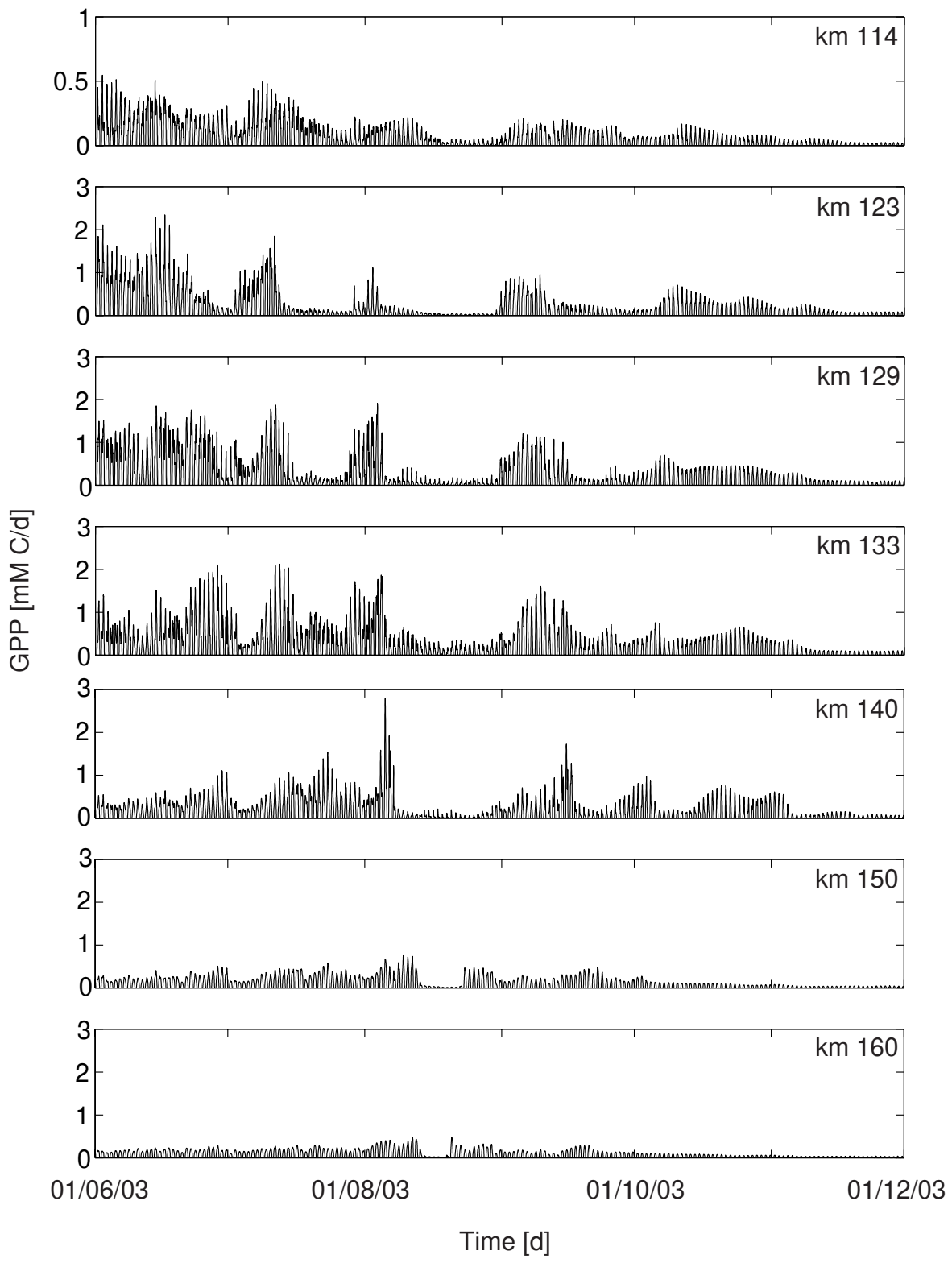

Fig. 6. Temporal evolution of gross primary production GPP at selected points in the tidal freshwater from June-December 2003.

decreases and remains low during winter (Fig. 6). Primary production in the Scheldt is never limited by nitrogen and phosphorus as a consequence of the high anthropogenic loads released into the estuary.

\subsubsection{Benthic silica dynamics in the Scheldt estuary}

BBSI in the estuarine surface sediments is generally low and varies from $0.05 \%$ to $1.5 \%$ (Chou and Wollast, 2006).

Measurements of interstitial silica profiles at two shallow intertidal sites along the estuarine gradient (February 2000August 2001; km 60 Waarde, km 133 Appels) merely cap- ture the seasonal dynamics of dissolved silica in the sediments (Fig. 7). The depth-average silica concentrations are low in spring, but reach values close to saturation in late summer/early autumn due to the deposition of biogenic silica derived from the pelagic summer bloom and its subsequent dissolution. They finally decrease again over the winter month concomitant with a drop in biogenic silica content and temperature.The extrapolation of the maximum benthic silica flux $\left(4.2 \times 10^{4} \mathrm{mmol} \mathrm{m}^{-2} \mathrm{~d}^{-1}\right)$, estimated from measured dissolved silica profiles at the Appels site (October 2000, Hyacinthe, personal communication) over the entire area of the tidal freshwater reaches, results in a silica flux of 


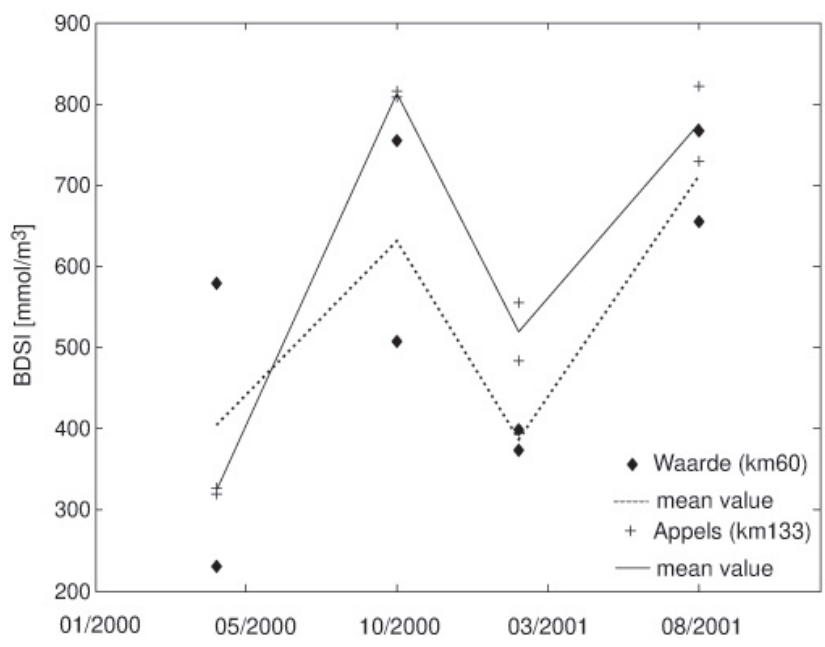

Fig. 7. Observed depth-averaged dissolved silica concentrations in two cores (single values are indicated by diamonds (Waarde), crosses (Appels)) at two sites in the Scheldt estuary (February 2000-August 2001, Hyacinthe, unpublished data).

$8.8 \times 10^{4} \mathrm{~mol} \mathrm{~d}^{-1}$. This maximum estimate exceeds the riverine silica input $\left(2.8 \times 10^{4}-8.8 \times 10^{4} \mathrm{~mol} \mathrm{~d}^{-1}\right)$ during the peak stage of the pelagic silica depletion in mid-August 2003, in line with the hypothesized importance of the silica recycling flux in summer 2003 (Desmit, 2005a; Van Damme et al., 2005; Muylaert et al., 2000).

The calibration and validation of the coupled model is hindered by the scarcity of field data. Yet, the sensitivity study reveals that the benthic dynamics are primarily controlled by the deposition/erosion fluxes of biogenic silica and thus of sediment, as well as by the dissolved silica concentration at the sediment/water interface. The pelagic model applied here gives a consistent description of the silica and SPM dynamics in the Scheldt estuary (Arndt et al., 2007). It therefore provides realistic boundary conditions for the benthic model and thus reduces the uncertainties in the estimation of benthic fluxes. In addition, the sensitivity analysis constraints the variability of the benthic flux response with respect to the most sensitive, internal model parameters $\left(\max k_{\mathrm{Si}}, D_{\mathrm{Si}}\right)$. The variabilities of max $\overline{\mathrm{BBSI}}(5 \%)$ and BDSI $(7.5 \%)$ are low over the range of observed dissolution rate constants $\left(\max k_{\mathrm{Si}}=[0.02-0.05] \mathrm{d}^{-1}\right)$ and realistic diffusion coefficients $\left(D_{\mathrm{Si}}=\left[35 \times 10^{-5}-35 \times 10^{-6} \mathrm{~m}^{2} \mathrm{~d}^{-1}\right]\right)$ (Fig. 4). For the same domain of the parameter space, the annually integrated dissolution rate $\int \bar{P}_{\text {diss }}$ and the preservation of BBSI fluctuate however by ca. $20 \%$, while the annually-integrated diffusive flux shows the highest variability $(75 \%)$. This variability is mainly associated with variations of the diffusion coefficient and varies merely $12 \%$ over a range of observed values of $\max k_{\mathrm{Si}}$. In addition, the variability of $\int F_{\mathrm{diff}}$ over the more suitable lower $\log \left(D_{\mathrm{Si}}\right)$ range $(<-4)$ is smaller $(33 \%)$ than over the upper $D_{\mathrm{Si}}$ range, where the steepest gradients in the parameter space are simulated (Fig. 4f).

\subsubsection{Benthic-pelagic coupling at the local scale}

Figure 8 illustrates the temporal evolution of the benthic silica dynamics at three selected locations $(\mathrm{S} 1=\mathrm{km} 121$, $\mathrm{S} 2=\mathrm{km} 129, \mathrm{~S} 3=\mathrm{km} \mathrm{150}$, see Fig. 1) in the tidal freshwater reaches of the Scheldt estuary over a period of half a year, starting in June 2003. Each station represents a different environment with a distinct temporal dynamics. S1 and S3 are both shallow sites, but $\mathrm{S} 1$ is situated in the vicinity of the estuarine energy minimum, while S3 is located in the upper reaches of the tidal river. $\mathrm{S} 2$ reflects the conditions in the deeper, tidal channel at the upstream limit of the energy minimum. A comparison of model results at these sites shows that the benthic dynamics is strongly dependent on the physical conditions that prevail in the overlying water column.

A net-accumulation of biogenic silica can generally be observed in shallow areas, where the low energetics in the water column favor the deposition of pelagic biogenic silica (Fig. 8a, c). Shallow areas around the energy minimum ( $\mathrm{km} \mathrm{120-km} \mathrm{130),} \mathrm{such} \mathrm{as} \mathrm{S1,} \mathrm{show} \mathrm{a} \mathrm{maximum} \mathrm{deposition}$ flux at the beginning of the growth period, when the local production reaches its maximum (Fig. 8a). However, this area is also a depositional trap for biogenic material flushed out of the upper tidal reaches. As a result, $\bar{P}_{\text {dep }}$ is relatively high and constant throughout the simulation period even after the end of the growth season in September. Further upstream (S3), the deposition flux reveals a distinct maximum which coincides with the local maximum in pelagic primary production in mid-August (Fig. 8c). It decreases to very low values at the end of the growth period in September.

The temporal dynamics of biogenic silica dissolution is directly linked to the temporal evolution of the deposition flux. The distribution of $\bar{P}_{\text {diss }}$ shows a characteristic seasonal cycle (Fig. 9a, b). At both locations, dissolution rates increase with the increasing deposition fluxes at the beginning of the summer bloom. Local maxima in dissolution rates coincide with maxima in deposition fluxes. The decrease in deposition fluxes later in the year results in decreasing dissolution rates (Fig. 9a, b). The detailed temporal dynamics however depends on the specific location within the estuary. At S1, the maximum deposition flux and, thus, the maximum dissolution rate is reached at the end of June, when the biogenic silica content in the upper centimeters of the sediment is high and the saturation state of the interstitial water low. The subsequent decrease is only interrupted by two distinct deposition peaks in July and September. However, the dissolution rate remains essentially constant during these excursions, due to the increased saturation state of the interstitial waters which slows down dissolution. At S3, maximum dissolution rates are reached in August. Fig. 9a, b shows that the distribution of dissolution rates over deposition fluxes is characterized by a higher degree of variability at this site. 
A
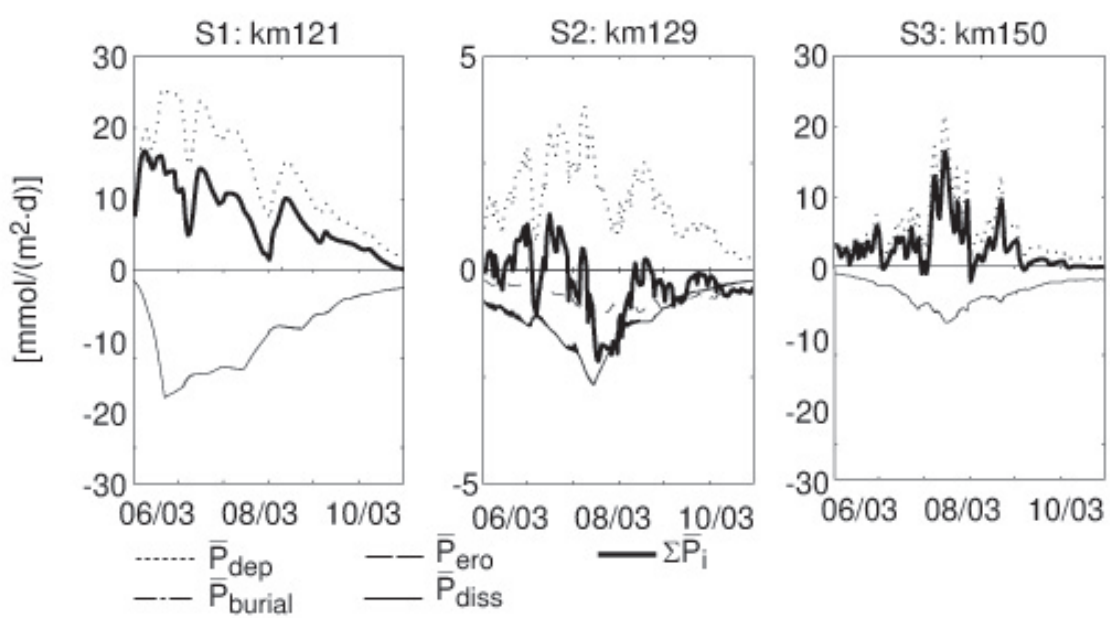

B
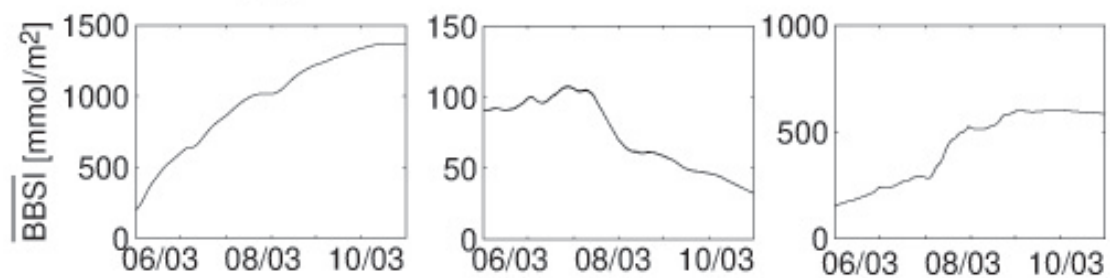

$\mathrm{C}$
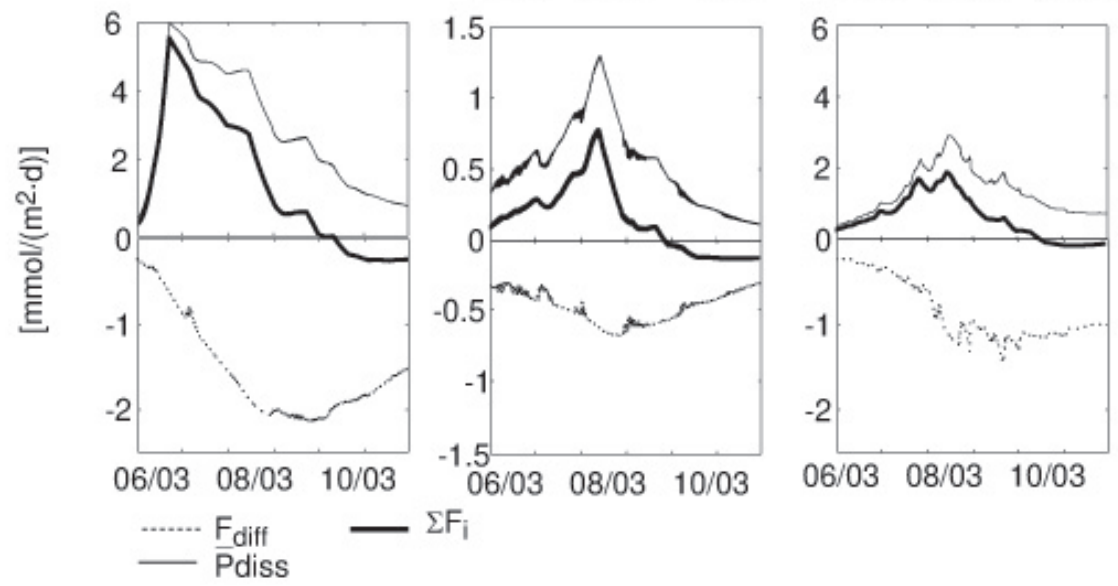

D
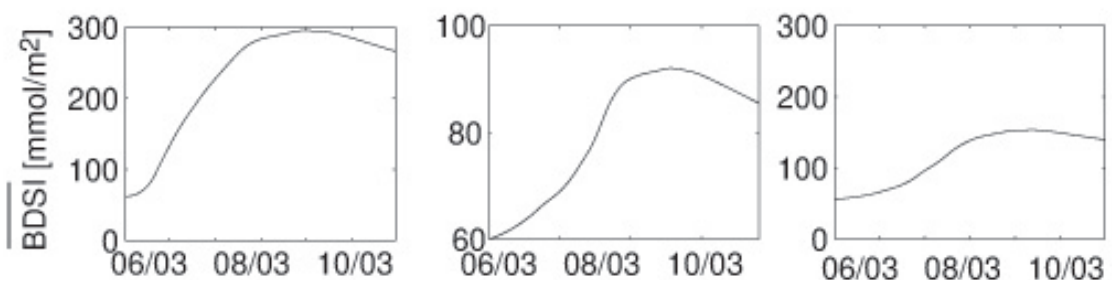

Fig. 8. Temporal evolution of (A) depth-integrated deposition flux $\bar{P}_{\text {dep }}$, erosion flux $\bar{P}_{\text {ero }}$, burial flux $\bar{P}_{\text {burial }}$, dissolution rate $P_{\text {diss }}$ and net rate $\sum_{i} \overline{P_{i}}$, (B) depth-integrated biogenic silica content $\overline{\mathrm{BBSI}}$, (C) depth-integrated dissolution rate $\bar{P}_{\text {diss }}$, diffusive flux $F_{\text {diff }}$, net rate of silica production/consumption and (D) depth-integrated dissolved silica concentration $\overline{\text { BDSI }}$ at three sites (S1, S2, S3, see Fig. 1) in the freshwater tidal reaches of the Scheldt. Simulation results correspond to the system scale parameter set (Table 2).

The variability is mainly introduced by fluctuations in river discharge, which influence the deposition flux as well as the silica concentration in the overlying water. Increasing river discharges lead to lower dissolution rates due to a reduced deposition and an increased saturation of interstitial waters in the upper centimeters, due to increasing concentrations at the sediment/water interface. 

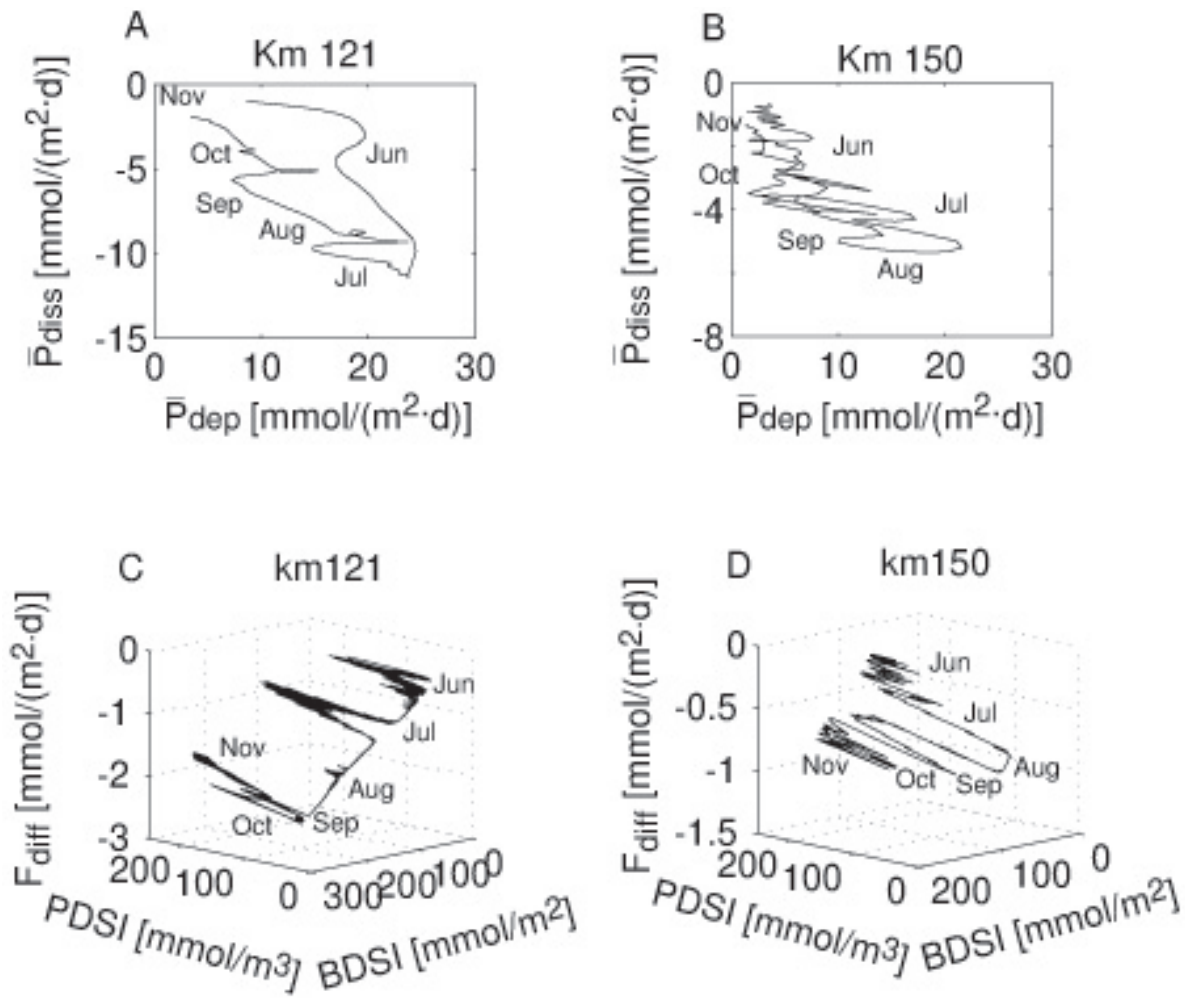

Fig. 9. Distribution of the depth-integrated silica dissolution rate $P_{\text {diss }}$ over the deposition flux $P_{\text {dep }}$ at (A) $\mathrm{km} 121$ (B) km 150 . Distribution of the diffusive silica flux $F_{\text {diff }}$ over the pelagic dissolved silica concentration PDSI and the depth-integrated benthic biogenic silica content $\overline{\mathrm{BBSI}}$ at (C) km 121 and (D) km 150. Simulation results correspond to the simulated period (01/06/2003-30/11/2003) and the system scale parameter set(Table 2).

In shallow areas, the deposition fluxes generally exceed the consumption of BBSI by dissolution and net rates remain positive during the simulation period (Fig. 8a, c). The constant deposition of biogenic silica at S1 leads to relatively high positive net rates and thus high biogenic silica contents in this area (Fig. 8a, c). Further upstream, biogenic silica only accumulates significantly during the period of high primary production in August and contents are therefore lower at S3. In contrast to shallow areas (S1, S3), sediments located in the tidal channel (S2) are characterized by negative net rates (Fig. 8b). Most of the mass transport occurs through these channels and maximum current velocities are high. They generally exceed the threshold velocity for deposition during most of the tidal cycle. Therefore, even though S2 is located in the vicinity of the energy minimum, deposition rates are low at these sites. In addition, high current velocities lead to the erosion of BBSI. A positive net rate is only achieved when the deposition of PBSI is favored by a high local production in June/July. During the remaining period, dissolution rates exceed the deposition and BBSI contents are also low (Fig. 8b).

The dissolution of the accumulating biogenic silica leads to a build-up of BDSI in the sediments (Fig. 8), since, as shown in the sensitivity study, the controlling mechanisms for biogenic silica dissolution and diffusive flux are different and act on different time scales (see 3.1.3). Dissolution rates exceeds the diffusive loss during the whole growth period and the net rate is thus positive. The rate becomes negative at the end of the productive period, when the deposition flux decreases as a consequence of the declining water column production, but diffusive fluxes remain high. Maximum diffusive fluxes are reached at the end of the growth period in September when the silica concentrations in the sediments are elevated as a result of high dissolution rates during the preceding month (Fig. 8a, c). Figure 9 c, d reveals that the diffusive fluxes are mainly controlled by the availability of silica in the sediments, as well as the silica concentration in the overlying water. At both sites, diffusive fluxes increase from June to September with increasing BDSI concentrations. However, short term excursions, which are triggered by increasing water column concentrations, are superimposed on this general increase. Similar to the $\bar{P}_{\text {dep }} / \bar{P}_{\text {diss }}$ distribution, diffusive fluxes reveal a higher degree of variability at $\mathrm{S} 3$. In this area, water column silica concentrations (PDSI, PBSI) respond quickly to changes in river discharge. In turn, pelagic conditions are more stable at $\mathrm{S} 1$ in the vicinity of the energy minimum, where PDSI concentrations remain low throughout most of the growth 

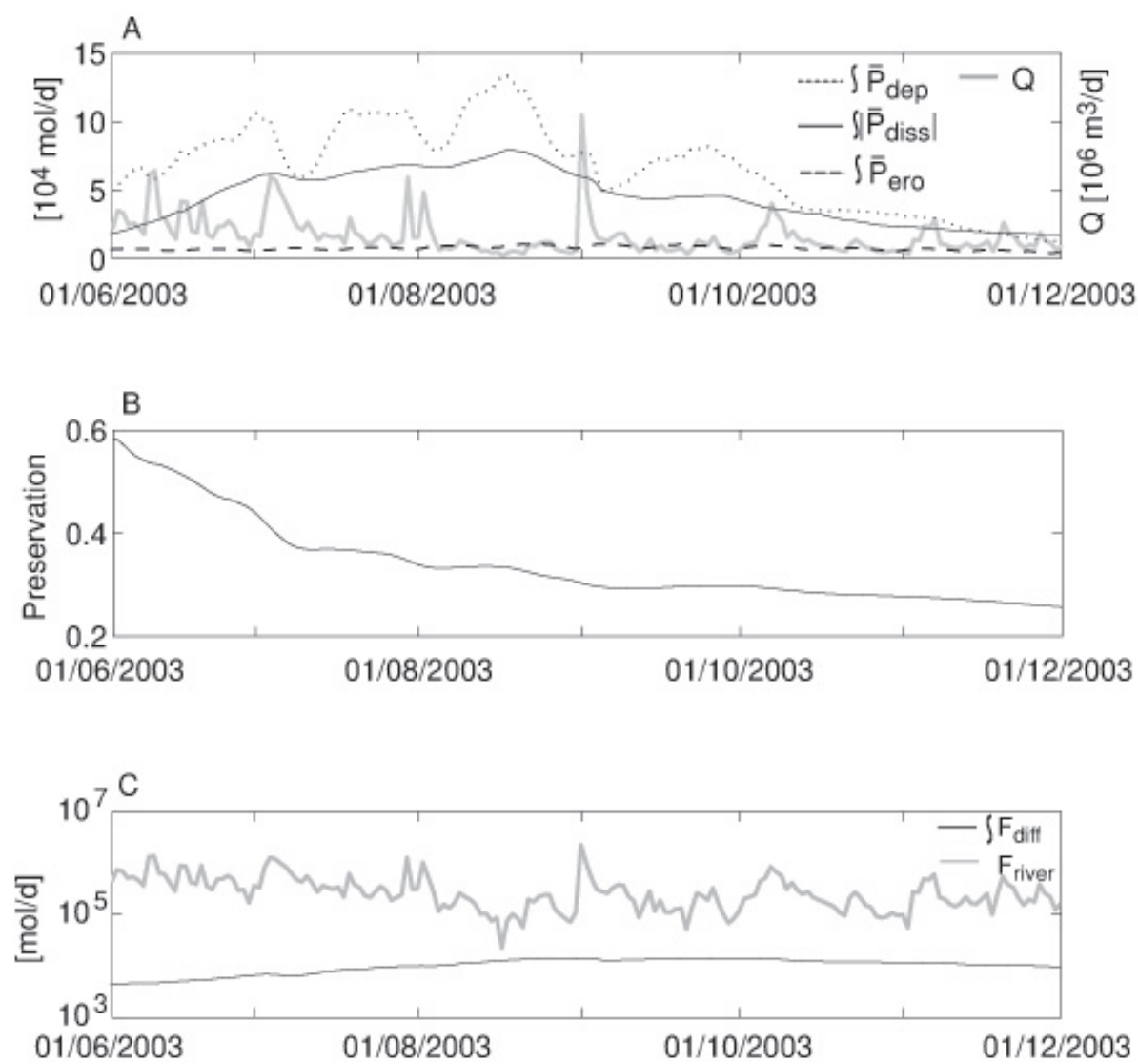

Fig. 10. Temporal evolution of (A) area-integrated depositional flux $\int \bar{P}_{\text {dep }}$, dissolution of biogenic silica $\int \bar{P}_{\text {diss }}$ and erosion flux $\int \bar{P}_{\text {ero }}$ in the freshwater tidal reaches $(\mathrm{km} \mathrm{170-km} \mathrm{100)}$ of the Scheldt estuary, as well as daily river discharge $Q$. (B) Preservation of deposited BBSI in the freshwater reaches. (C) Comparison of logarithmic, area-integrated (km 170-km 100) diffusive flux of silica and logarithmic, daily riverine (Scheldt + Dender) silica influx into the tidal freshwater reaches of the Scheldt.

season (June-September). In the tidal channel, low dissolution rates result in very low BDSI concentrations and low diffusive fluxes (not shown).

\subsubsection{Benthic-pelagic coupling at the system scale}

Figure 10 illustrates the temporal evolution of processes and fluxes, integrated over the freshwater tidal reaches of the estuary $(\mathrm{km} \mathrm{170-100).} \mathrm{Similar} \mathrm{to} \mathrm{the} \mathrm{local} \mathrm{benthic} \mathrm{dynam-}$ ics, the area integrated transformation processes reflect the influence of water column conditions on the benthic dynamics. The area-integrated deposition of biogenic silica in the tidal freshwater reaches of the Scheldt estuary $\left(\int \bar{P}_{\text {dep }}\right)$ is driven by the combined influence of pelagic production and river discharge (Fig. 10a). Deposition is high throughout the whole growth season and a total of $1.2 \times 10^{7} \mathrm{~mol}$ (=742 $\mathrm{mmol} \mathrm{m}^{-2}$ per unit surface area) PBSI are deposited over the simulated period in the tidal freshwater reaches. However, $\int \bar{P}_{\text {dep }}$ reveals variabilities which are induced by variations in river discharge. Low river discharges reduce the hydrodynamic energy and thus favor deposition and potentially pelagic primary production (Arndt et al., 2007).

High river discharge has an opposite effect and leads therefore to a reduction of biogenic silica deposition. A maximum in deposition flux $\left(1.3 \times 10^{5} \mathrm{~mol} \mathrm{~d}^{-1}\right)$ is reached in mid-August, even though silica depletion in the tidal river maintains low pelagic primary production at this time (Arndt et al., 2007). The high $\int \bar{P}_{\text {dep }}$ must therefore originate from biogenic silica produced a few weeks before and which mainly settles in the upper tidal reaches due to extremely low river discharges $\left(<5 \mathrm{~m}^{3} \mathrm{~s}^{-1}\right)$ during this period. The deposition of biogenic silica decreases in fall and dissolution becomes of similar magnitude in mid-October (Fig. 10a). In general, dissolution rates respond with a significant dampening and a small delay $(<7 \mathrm{~d})$ to variations in $\int \bar{P}_{\mathrm{dep}}$ (Fig. 10a). A total of $8 \times 10^{6} \mathrm{~mol}\left(=486 \mathrm{mmol} \mathrm{m}^{-2}\right)$ BBSI are dissolved in the freshwater reaches from June to December 2003. The magnitude of erosion fluxes $\left(10^{3} \mathrm{~mol} \mathrm{~d}^{-1}\right)$ is one to two orders of magnitude lower than those of $\int \bar{P}_{\mathrm{dep}}$ and $\int \bar{P}_{\text {diss }}$ (Fig. 10a). The total erosive flux removes 


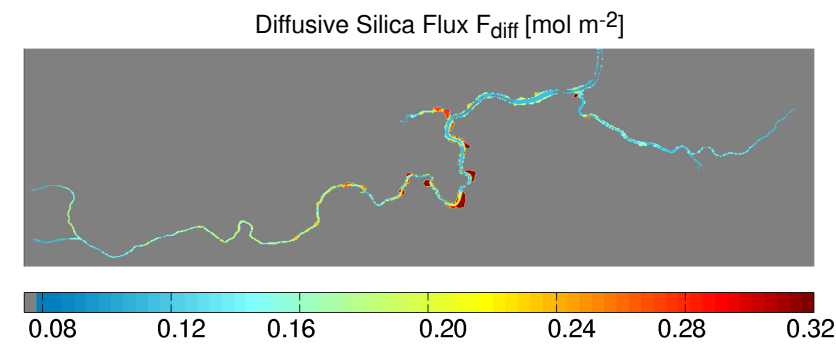

Fig. 11. Distribution of integrated (June-November 2003) diffusive silica fluxes $F_{\text {diff }}$ in the tidal freshwater reaches of the Scheldt estuary.

$1 \times 10^{6} \mathrm{~mol}\left(=67 \mathrm{mmol} \mathrm{m}^{-2}\right)$ of BBSI from the sediments. Most of the biogenic silica deposited in the tidal freshwater reaches is consumed in this stretch during the simulated period (Fig. 10b). A small fraction (ca. 27\%) of the deposition flux is preserved in the estuarine sediments at the beginning of December.

The diffusive silica flux ( $\left.\int F_{\text {diff }}\right)$ increases steadily during the first half of the simulated period and reaches its maximum value one month after the maximum in $\int \bar{P}_{\text {dep }}$ and $\int \bar{P}_{\text {diss }}$, at the end of the growth period (Fig. 10c). However, compared to the riverine silica influx $\left(F_{\text {river }}\right)$, benthic recycling fluxes are of minor importance. Overall, the riverine input exceeds the diffusive silica flux by about two orders of magnitude. $F_{\text {riv }}$ and $\int F_{\text {diff }}$ are of the same order of magnitude only in mid-August, when extremely low river discharges reduce the riverine silica influx to minimum values. During the simulated period (June-November 2003) a total of $5.9 \times 10^{7} \mathrm{~mol}$ is supplied by the freshwater input, while the spatially integrated benthic diffusive flux only accounts for a total $2 \times 10^{6} \mathrm{~mol}$. Thus, the benthic recycling fluxes account for a mere $3.6 \%$ of the total dissolved silica flux discharged into the tidal freshwater reaches of the Scheldt estuary. The simulated contribution of the benthic environment to the silica cycling on the system scale is significantly smaller than the one estimated by extrapolating local flux measurements to the system scale (Struyf et al. (2005), 3.2.3), without accounting for the heterogeneity of the benthic environment. Figure 11 shows the distribution of the integrated (JuneNovember 2003) benthic silica flux per unit surface area in the tidal freshwater reaches. The highest diffusive silica fluxes are simulated in shallow areas around the energy minimum ( $\mathrm{km} \mathrm{120-km} \mathrm{130),} \mathrm{where} \mathrm{hydrodynamic} \mathrm{conditions} \mathrm{fa-}$ vor deposition and local production is generally high. Fluxes from the sediments located in the main channel sediments and in the upstream areas are significantly smaller due to lower deposition fluxes, higher erosion rates and the lower primary production.

The high riverine loads of dissolved silica decrease the relative importance of benthic-pelagic coupling for the systemscale pelagic primary production. Figure 12 illustrates the difference between the simulated GPP with and without benthic-pelagic coupling during August and September, when benthic recycling fluxes reach their annual maximum and the riverine silica influx is low. The difference in GPP between these two simulations is maximum in mid-August, when the reduced riverine silica input leads to a silica depletion in the freshwater reaches. However, the coupled benthicpelagic model merely increases the gross primary production by $10 \%$ during this period. In addition, in mid-August, gross primary production rates are roughly one order of magnitude lower than during most of the growth period (Fig. 12a). The difference in GPP between the beginning of August and September, when high GPP rates are reached again, is thus much lower (Fig. 12b). The time-integrated difference in GPP, increases to $1 \%$ at the end of August before it decreases again in September and reaches $0.7 \%$ at the end of September. Struyf et al. (2005) estimated that the export of dissolved silica from freshwater marshes may provide an important source of dissolved silica in the summer month, when the silica concentration in the upper freshwater reaches is low. Simulation results showed that during the the silica depletion period in mid-August, diffusive silica fluxes can constitute almost half of the dissolved silica load in the tidal freshwater reaches. Yet, the area of freshwater marshes and the magnitude of the diffusive silica fluxes are too small to maintain an elevated pelagic primary production on the system scale. Therefore, the benthic recycling of silica sustains only a small fraction $(<1 \%)$ of the total pelagic primary production in the Scheldt estuary and the benthic-pelagic coupling is thus of minor importance on the system scale.

\section{Conclusions}

A transient, vertically resolved, early diagenetic model for silica which accounts for biogenic silica dissolution, mixing by diffusion and bioturbation, as well as deposition and erosion of unconsolidated sediments has been developed. The method of resolution is robust, analytical and cost-efficient. The benthic model is therefore particularly suitable to quantify the importance of the benthic-pelagic coupling in estuarine and coastal systems that are characterized by a high degree of spatial heterogeneity. In the present study, the model has been coupled to a two-dimensional reactive-transport model of the pelagic diatom production in the Scheldt estuary.

A sensitivity study based on Monte-Carlo simulations has been performed to assess the relative importance of internal model parameters and external forcing (i.e. pelagic conditions) on benthic dynamics. The latter has been evaluated on the basis of dissolution rates, diffusive silica fluxes, preservation efficiencies and biogenic silica contents. The time lags between the deposition signal and the benthic response have also been addressed. 

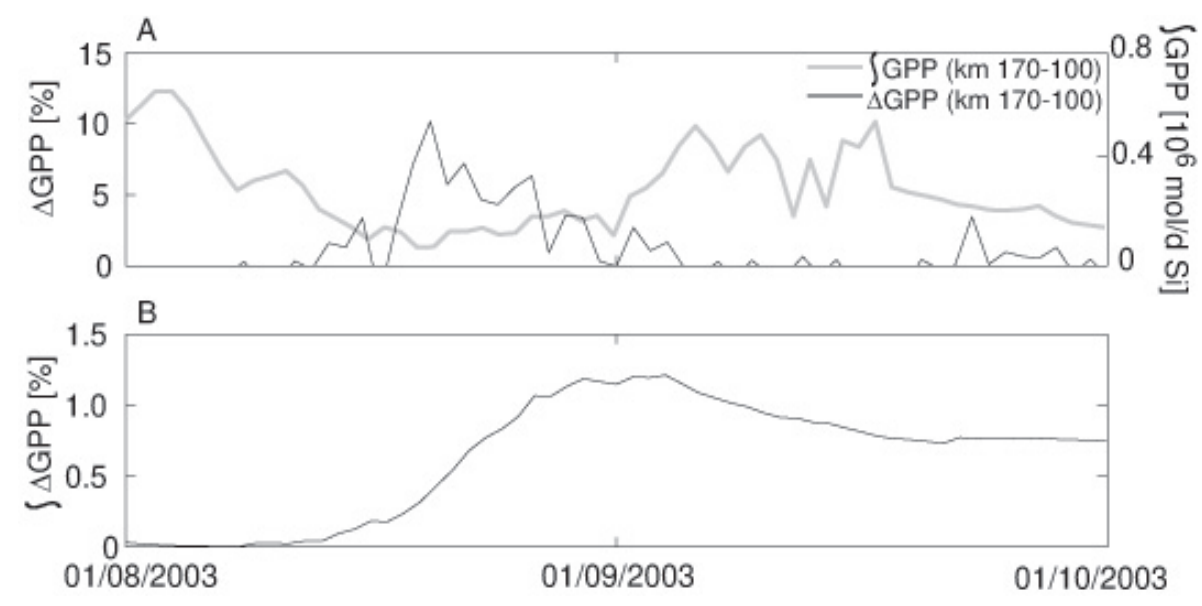

Fig. 12. Temporal evolution of (A) area-integrated $\left(\mathrm{km} \mathrm{170-km} \mathrm{100)} \mathrm{gross} \mathrm{primary} \mathrm{production} \int\right.$ GPP, simulated with the benthic-pelagic model and daily percentage increase of simulated GPP of the benthic-pelagic model compared to the pelagic model $\Delta$ GPP. (B) timeintegrated percentage increase of simulated GPP of the benthic-pelagic model compared to the pelagic model $\int \Delta$ GPP.

Results show that the dissolution rate responds quickly to variations in deposition fluxes that depend on pelagic processes, such as production and hydrodynamics. In turn, diffusive return fluxes occur with a delay, whose magnitude depends on reaction kinetics and diffusion. In addition, the benthic fluxes reveal variations associated with the variability in pelagic silica concentrations. Results show that the tightness of the benthic pelagic coupling is mainly controlled by reaction kinetics. High dissolution rate constants lead to a very tight coupling which completely determines the benthic dynamics. However, transport processes gain in importance with decreasing dissolution rate constants.

System scale simulations of the biogeochemical dynamics in the Western Scheldt between June and December 2003 show significantly different dynamics in shallow areas and tidal channels. In the Scheldt, benthic processes along the estuarine gradient are mainly determined by the combined influence of local hydrodynamic conditions and pelagic primary production dynamics. While areas of low hydrodynamic energy receive a relatively constant deposition flux of biogenic silica, elevated deposition fluxes in the upstream areas, dominated by fluvial energy, only occur when local pelagic primary production is high. Spatially integrated deposition fluxes and dissolution rates of biogenic silica over the whole tidal river reveal high values throughout the growth period. Maxima are reached in mid-August when pelagic primary production is maximum and fluvial energy input low. Only a small fraction (ca. 27\%) of the deposited silica is preserved in the estuarine sediments at the end of the simulated period. The spatially integrated diffusive flux reaches its maximum at the end of a pelagic silica depletion period in September 2003. Over the simulated period, the benthic recycling flux is however of minor importance $(3.6 \%)$ compared to the much higher riverine influx of dissolved silica.
However, the sensitivity study showed that the uncertainty of the benthic flux response can be as high as $75 \%$ over a realistic range of internal parameter values for the estuarine environment. Nevertheless, a $75 \%$ increase of the diffusive flux would still only represent $5.9 \%$ of the riverine dissolved silica input. Thus, the conclusion also holds for the whole range of variability associated with the benthic flux. The simulated relative contribution of the benthic silica flux to the total input of dissolved silica is thus significantly smaller than one estimated based on the extrapolation of a local silica flux (ca. 21\%). An extrapolation of a local silica flux to the system scale or even morphologically similar environments is therefore questionable. Results of the system scale simulations, with and without benthic-pelagic coupling, reveal that the diffusive flux merely leads to a $0.7 \%$ increase of pelagic gross primary production during August and September. 


\section{Appendix A}

\begin{tabular}{|c|c|}
\hline Symbol & Description \\
\hline BBSI & benthic biogenic silica concentration \\
\hline BDSI & benthic dissolved silica \\
\hline PBSI & pelagic biogenic silica \\
\hline PDSI & pelagic dissolved silica \\
\hline$\overline{\mathrm{BBSI}}$ & depth-integrated biogenic silica concentration \\
\hline$\overline{\mathrm{BDSI}}$ & depth-integrated dissolved silica concentration \\
\hline ID & intrusion depth \\
\hline DIA & diatom concentration \\
\hline SPM & suspended particulate matter concentration \\
\hline$z$ & sediment depth \\
\hline$z_{\max }$ & maximum depth of the sediment column \\
\hline$z_{\text {ero }}$ & thickness of the eroded sediment layer \\
\hline$z_{\text {dep }}$ & thickness of the deposited sediment layer \\
\hline$t$ & time step \\
\hline$t_{a}$ & adaption time \\
\hline $\bar{P}_{i}$ & depth-integrated consumption/production process of BBSI \\
\hline $\bar{P}_{\text {diss }}$ & depth-integrated dissolution rate of BBSI \\
\hline $\bar{P}_{\text {ero }}$ & depth-integrated erosion rate of BBSI \\
\hline $\bar{P}_{\mathrm{dep}}$ & depth-integrated deposition rate of BBSI \\
\hline $\bar{P}_{\text {burial }}$ & depth-integrated burial rate of BBSI \\
\hline $\bar{P}_{\text {biot }}$ & depth-integrated bioturbation rate of BBSI \\
\hline$k_{\mathrm{Si}}$ & dissolution rate constant for BBSI dissolution \\
\hline $\max k_{\mathrm{Si}}$ & maximum dissolution rate constant for BBSI dissolution \\
\hline$D_{\mathrm{Si}}$ & apparent diffusion coefficient for dissolved silica \\
\hline $\mathrm{BDSI}_{\mathrm{sat}}$ & apparent silica solubility \\
\hline$\gamma$ & bioturbation depth \\
\hline$D_{\text {bio }}$ & physical mixing \\
\hline$k_{0}$ & pre-exponential factor \\
\hline$E_{a}$ & empirical activation energy \\
\hline$R$ & gas constant \\
\hline$T$ & temperature \\
\hline$\Phi$ & porosity \\
\hline$\rho$ & sediment density \\
\hline$h$ & water depth \\
\hline$v$ & depth-averaged, horizontal velocity vector \\
\hline$D_{s}$ & horizontal dispersion coefficient \\
\hline$R_{\text {ero }}$ & erosion rate of SPM \\
\hline$R_{\text {dep }}$ & deposition rate of SPM \\
\hline$p_{\text {ero }}$ & probability of erosion \\
\hline$p_{\text {dep }}$ & probability of deposition \\
\hline$M$ & erosion constant \\
\hline$\tau_{\mathrm{crd}}$ & critical shear stress \\
\hline$\rho_{\mathrm{SPM}}$ & density of SPM \\
\hline$\eta$ & water viscosity \\
\hline$g$ & acceleration due to gravity \\
\hline$\rho_{w}$ & density of water \\
\hline NPP & net primary production rate \\
\hline GPP & gross primary production rate \\
\hline$k_{\text {mortality }}$ & mortality rate of DIA \\
\hline$w_{\text {DIA }}$ & settling velocity of dead DIA \\
\hline $\mathrm{Si}: \mathrm{C}$ & silica to carbon ratio \\
\hline$h_{\text {PBSI }}$ & height of PBSI peak \\
\hline$w_{\text {PBSI }}$ & width of PBSI peak \\
\hline$l_{\mathrm{PDSI}}$ & background concentration of PDSI \\
\hline$h_{\text {PBSI }}$ & height of PDSI peak \\
\hline$w_{\text {PBSI }}$ & width of PDSI peak \\
\hline
\end{tabular}

Acknowledgements. This study has been financially supported by the Institute of Earth Sciences Utrecht (IVAU). The authors would like to thank C. Hyacinthe for providing silica measurements from the Appels and Waarde sites. We also want to thank two anonymous reviewers and $\mathrm{M}$. Dai for their review and editorial advice.

Edited by: M. Dai

\section{References}

Abramowitz, M. and Stegun, I. A.: Handbook of mathematical functions, 9th Edition, Dover Publications, New York, 1972.

Abril, G., Riou, S. A., and Etcheber, H.: Transient, tidal time-scale, nitrogen transformations in an estuarine turbidity maximum-fluid mud system (the Gironde, South-West France), Estuarine, Coast. Shelf Sci., 50, 703-715, 2000.

Ariathurai, C. R.: Finite element model for sediment transport in estuaries, Phd thesis, University of California, 1974.

Arndt, S., Vanderborght, J.-P., and Regnier, P.: Diatom growth response to physical forcing in a macrotidal estuary: Coupling hydrodynamics, sediment transport, and biogeochemistry, J. Geophys. Res., 112, C05045, doi:10.1029/2006JC003581, 2007.

Baeyens, W., Van Eck, B., Lambert, C., Wollast, R., and Goyens, L.: General description of the Scheldt, Hydrobiologia, 366, 114, 1998.

Baird, M.: Csiro simple estuarine response model technical description of the ecological model, Tech. rep., CSIRO Marine Research, 2001.

Berner, R. A.: Early Diagenesis: A theoretical approach, Princeton University Press, Princeton, 1980.

Blackford, J.: An analysis of benthic biological dynamics in a North Sea ecosystem model, J. Sea Res., 38, 213-230, 1997.

Chen, M. S., Wartel, S., Van Eck, B., and Van Maldegem, D. C.: Suspended matter in the Scheldt estuary, Hydrobiologia, 540, 79-104, 2005.

Chou, L. and Wollast, R.: Estuarine silicon dynamics, in: The Silicon Cycle: Human Perturbations and Impacts on Aquatic Systems, edited by: Ittekkot, D., Unger, C., Humborg, C., and Tac An, N., Vol. Scope 66, Island Press, Washington, Covelo, London, pp. 93-120, 2006.

Conley, D. J., Smith, W. M., Cornwell, J. C.: Transformation of particle-bound phosphorus at the land sea interface. Estuarine, Coast. Shelf Sci., 40, 161-176, 1995.

Cowan, J. L. and Boynton, W. R.: Sediment-water oxygen and nutrient exchange along the longitudinal axis of Chesapeake Bay: Seasonal patterns, controlling factors and ecological significance, Estuaries 19, 562-580, 1996.

Desmit, X., Vanderborght, J. P., Regnier, P., and Wollast, R.: Control of primary production by physical forcing in a strongly tidal, well-mixed estuary, Biogeosciences, 2, 205-218, 2005, http://www.biogeosciences.net/2/205/2005/.

Desmet, X.: Etude et modélisation de la production phytoplanctonique dans l'estuaire de l'Escaut, Phd thesis, Université Libre de Bruxelles, 2005.

Dettman, E. H.: Effect of water residence time on annual export and denitrification in estuaries: A model analysis, Estuaries 24, 481-490, 2001. 
Domingues, R. B., Barbosa, A., and Galvao, H.: Nutrients, light and phytoplankton succesion in a temperate estuary (the Guadiana, South-Western Iberia). Estuarine, Coast. Shelf Sci., 64, 249-260, 2005.

Ebenhöh, W., Kohlmeier, C., Radford, P. J.: The benthic biological submodel in the european regional seas ecosystem model, Neth. J. Sea Res., 33, 423-452, 1995.

Einstein, H. B. and Krone, R. B.: Experiments to determine modes of cohesive sediment transport in salt water, J. Geophys. Res., 67(4), 1451-1461, 1962.

Ekebjaerg, L. and Justesen, P.: An explicit scheme for advectiondiffusion modelling in two dimensions, Comput. Methods Appl. Mech. Eng., 88, 3-8, 1991.

Fennel, K., Wilkin, J., Levin, J., Moisan, J., O’Reilly, J., and Haidvogel, D.: Nitrogen cycling in the middle Atlantic bight: Results from a three-dimensional model and implications for the North Atlantic nitrogen budget, Global Biogeochem. Cy., GB3007, doi:10.1029/2005GB002456, 2005.

Garnier, J., Billen, G., Coste, M.: Seasonal succession of diatoms and chlorophyceae in the drainage network of the Seine river: Observations and modeling, Limnol. Oceanogr., 40, 750-765, 1995.

Grenz, C., Cloern, J. E., Hager, S. W., and Cole, B. E.: Dynamics of nutrient cycling and related benthic nutrient and oxygen fluxes during a spring phytoplankton bloom in south San Francisco Bay (USA), Marine Ecology Progress Series 197, 67-80, 2000.

Hall, P. O. J., Hulth, S., Hulthe, G., Landen, A., Tengberg, A.: Benthic nutrient fluxes on a basin-wide sclae in the Skagerrak (northeastern North Sea), J. Sea Res., 35, 123-137, 1996.

Hansen, L. S. and Blackburn, T. H.: Effect of algal bloom deposition on sediment respiration and fluxes, Mar. Biol., 112, 147$152,1992$.

Hurd, D. C.: Interactions of biogenic opal, sediment and seawater in the Central Equatorial Pacific, Geochimica et Cosmochimica Acta, 37, 2257-2282, 1973.

Icenhower, J. P. and Dove, P. M.: The dissolution kinetics of amorphous silica into sodium chloride solutions: Effects of temperature and ionic strength, Geochimica et Cosmochimica Acta, 64, 4193-4203, 2000.

Jeuken, M. C. J. L.: On the behaviour of tidal channels in the Westerschelde estuary, Phd thesis, Utrecht University, 2000.

Koop, K., Boynton, W. R., Wulff, F., and Carman, R.: Sedimentwater oxygen and nutrient exchange along a depth gradient in the Baltic Sea, Marine Ecology Progress Series, 63, 65-77, 1990.

Lancelot, C., Spitz, Y., and Gypens, N.: Modelling diatom and phaeocystis blooms and nutrient cycles in the southern bight of the North Sea: The MIRO model, Marine Ecology Progress Series, 289, 63-78, 2005.

Lee, J.-Y., Tett, P., Jones, K., Jones, S., Luyten, P., Smith, C., and Wild-Allen, K.: The PROWQM physical-biological model with benthic-pelagic coupling applied to the northern North Sea, J. Sea Res., 48, 287-331, 2002.

Li, Y. H. and Gregory, S.: Diffusion of ions in sea-water and deepsea sediments, Geochimica et Cosmochimica Acta, 38, 703-714, 1974.

Luff, R. and Moll, A.: Seasonal dynamics of the North Sea sediments using a three-dimensional coupled sediment-water model system, Cont. Shelf Res., 24, 1099-1127, 2004.

Malone, T. C., Conley, D. J., Fisher, T. R. J., Gilbert, P. M., and
Harding, L. W.: Scales of nutrient-limited phytoplankton productivity in Chesapeake Bay, Estuaries, 19, 371-385, 1996.

McKee, L. J., Eyre, B. D., and Hossain, S.: Transport and retention of nitrogen and phosphorus in the sub-tropical Richmond river estuary, Biogeochemistry, 50, 241-278, 2000.

Meire, P., Ysebaert, T., Van Damme, S., Van den Bergh, E., Maris, T., and Struyf, E.: The Scheldt estuary: A description of a changing ecosystem, Hydrobiologia, 540, 1-11, 2005.

Muylaert, K., Tackx, M. L., and Vyeverman, W.: Phytoplankton growth rates in the freshwater tidel reaches of the Schelde estuary (Belgium) estimated using a simple light-limited primary production model, Hydrobiologia, 540, 127-140, 2005.

Muylaert, K., Sabbe, K., and Vyeverman, W.: Spatial and temporal dynamics of phytoplankton communities in a freshwater tidal estuary (Schelde, Belgium), Estuarine and Coastal Shelf Sciences, 50, 673-687, 2000.

Partheniades, E.: A study of erosion and deposition of cohesive soils in salt water, Ph.D. thesis, University of California, 1962.

Press, W. H., Teukolsky, S. A., Vetterling, W. T., Flannery, B. P.: Numerical Recipies in C: The Art of Scientific Programming, Cambridge University Press, England, 1992.

Regnier, P., Wollast, R., and Steefel, C. I.: Long-term fluxes of reactive species in macrotidal estuaries: Estimates from a fully transient, multicomponent reaction-transport model, Mar. Chem., 58, 127-145, 1997.

Rousseau, V., Leynaert, A., Daoud, N., Lancelot, C.: Diatom succession, silification and silicic acid availability in Belgian coastal waters (southern North Sea), Marine Ecology Progress Series, 236, 61-73, 2002.

Ruardij, P. and Van Raaphorst, W.: Benhtic nutrient regeneration in the ERSEM ecosystem model of the North Sea, Neth. J. Sea Res., 33, 453-483, 1995.

Sakamaki, T., Nishimura, O., and Sudo, R.: Tidal time-scale variation in nutrient flux across the sedimeny-water interface of an estuarine tidal flat, Estuarine, Coastal and Shelf Science, 67, 653663, 2006.

Schink, D. R., Guinasso, N. L., and Fanning, K. A.: Processes affecting the concentration of silica at the sediment-water interface in the Atlantic Ocean, Geophys. Res., 80, 3013-3031, 1975.

Struyf, E., Van Damme, S., Gribsholt, B., and Meire, P.: Freshwater marshes as dissolved silica recyclers in an estuarine environment (Schelde estuary, Belgium), Hydrobiologia, 540, 69-77, 2005.

Soetaert, K. and Herman, P.: Nitrogen dynamics in the Westerschelde estuary (SW netherlands estimated by means of the ecosystem model MOSES, Hydrobiologia, 311, 225-246, 1995.

Soetaert, K. and Herman, P. M. J.: Carbon flows in the Westerschelde estuary (The Netherlands) evaluated by means of an ecosystem model (MOSES), Hydrobiologia, 311, 247-266, 1995 a.

Soetaert, K. and Herman, P. M. J.: Estimating estuarine residence times in the Westerschelde (The Netherlands) using a box model with fixed dispersion coefficients, Hydrobiologia, 311, 215-224, 1995b.

Townsend, D. W., Pettigrw, N. R., Thomas, A. C.: Offshore blloms of the red tide dinoflagellate, alexandrium sp., in the Gulf of Maine, Cont. Shelf Res., 21, 347-369, 2001.

Trimmer, M., Nedwell, D. B., Sivyer, D. B., and Malcolm, S. J.: Nitrogen fluxes through the lower estuary of the river Great Ouse, England: The role of the bottom sediments, Marine Ecology 
Progress Series, 163, 109-124, 1998.

Tuominen, L., Kairesalo, T., Hartikainen, H., and LTallberg, P.: Nutrient fluxes and microbial activity in sediment enriched with settled seston. Hydrobiologia, 335, 19-31, 1996.

Uncles, R. J., Wood, R. G., and Stephens, J. A: Estuarine nutrient fluxes to the Humber coastal zone, UK, during June 1995, Mar. Poll. Bull., 37, 3-7., 1998.

Van Cappellen, P. and Qiu, L.: Biogenic silica dissolution in sediments of the Southern Ocean. II. Kinetics, Deep-Sea Res. II, 44, 1129-1149, 1997.

Van Damme, S., Struyf, E., Maris, T., Ysebaert, T., Dehairs, F., Tackx, M., Heip, C., and Meire, P.: Spatial and temporal patterns of water quality along the estuarine salinity gradient of the Scheldt estuary (Belgium and The Netherlands): results of an integrated monitoring approach, Hydrobiologia, 540, 29-45, 2005.

Vanderborght, J. P., Folmer, I., Aguilera, D. R., Uhrenholdt, T., Regnier, P.: Reactive-transport modelling of $\mathrm{C}, \mathrm{N}$ and $\mathrm{O}_{2}$ in a river-estuarine-coastal zone system: Application to the Scheldt estuary, Mar. Chem., in press, 2006.
Vidal, M. and Morgui, J.-A.: Close and delayed benthic-pelagic coupling in coastal ecosystems: The role of physical constraints, Hydrobiologia, 429, 105-113, 2000.

Villars, M. T. and Vos, R. J.: Restwes: Remote sensing as a tool for integrated monitoring of the Western Scheldt, Tech. rep., WL Delft Hydraulics report Z2472, 1999.

Winterwerp, J. C., Wang, Z. B., Stive, M. J. F., Arends, A., Jeuken, C., Kuijper, C., and Thoolen, P. M. C.: A new morphological schematization of the Western Scheldt estuary, The Netherlands. In: Proceedings 2nd IAHR Symposium on River, Coastal and Estuarine Morphodynamics, Obihiro, Japan, pp. 525-534, 2001.

Wirtz, K. W.: Modellierung von Anpassungsvorgängen in der belebten Natur, Phd thesis, Universität Kassel, 1997.

Wirtz, K. W. and Eckhardt, B.: Effective variables in ecosystem models with an application to phytoplankton succesion, Ecol. Model., 92, 33-53, 1996.

Wollast, R. and Mackenzie, F. T.: Global cycle of silica, in: Silicon geochemistry and biogeochemistry, edited by: Aston, S. R., Academic Press, New York, pp. 39-76, 1983. 